\title{
Pathways to mental health services for young people: a systematic review
}

\author{
Kathleen MacDonald ${ }^{1,2} \cdot$ Nina Fainman-Adelman ${ }^{1,2} \cdot$ Kelly K. Anderson $^{3,4} \cdot$ Srividya N. Iyer $^{1,2}$
}

Received: 9 May 2018 / Accepted: 30 July 2018 / Published online: 22 August 2018

(c) The Author(s) 2018

\begin{abstract}
Purpose While early access to appropriate care can minimise the sequelae of mental illnesses, little is known about how youths come to access mental healthcare. We therefore conducted a systematic review to synthesise literature on the pathways to care of youths across a range of mental health problems.

Methods Studies were identified through searches of electronic databases (MEDLINE, PsycINFO, Embase, HealthSTAR and CINAHL), supplemented by backward and forward mapping and hand searching. We included studies on the pathways to mental healthcare of individuals aged 11-30 years. Two reviewers independently screened articles and extracted data.

Results Forty-five studies from 26 countries met eligibility criteria. The majority of these studies were from settings that offered services for the early stages of psychosis, and others included inpatient and outpatient settings targeting wide-ranging mental health problems. Generally, youths' pathways to mental healthcare were complex, involved diverse contacts, and, sometimes, undue treatment delays. Across contexts, family/carers, general practitioners and emergency rooms featured prominently in care pathways. There was little standardization in the measurement of pathways.

Conclusions Except in psychosis, youths' pathways to mental healthcare remain understudied. Pathways to care research may need to be reconceptualised to account for the often transient and overlapping nature of youth mental health presentations, and the possibility that what constitutes optimal care may vary. Despite these complexities, additional research, using standardized methodology, can yield a greater understanding of the help-seeking behaviours of youths and those acting on their behalf; service responses to help-seeking; and the determinants of pathways. This understanding is critical to inform ongoing initatives to transform youth mental healthcare.
\end{abstract}

Keywords Youth mental health $\cdot$ Mental health services $\cdot$ Pathways to care $\cdot$ Help-seeking behaviour $\cdot$ Treatment delays

Electronic supplementary material The online version of this article (https://doi.org/10.1007/s00127-018-1578-y) contains supplementary material, which is available to authorized users.

Srividya N. Iyer

srividya.iyer@mcgill.ca

1 Department of Psychiatry, McGill University, Montreal, QC, Canada

2 Prevention and Early Intervention Program for Psychosis (PEPP) and ACCESS Open Minds (pan-Canadian youth mental health services research network), Douglas Mental Health University Institute, Montreal, QC, Canada

3 Department of Epidemiology and Biostatistics, The University of Western Ontario, London, ON, Canada

4 Department of Psychiatry, The University of Western Ontario, London, ON, Canada

\section{Introduction}

Most psychiatric conditions emerge before the age of 25 [1]. Mental illness is the largest contributor to the burden of disability-adjusted life years (DALYs) among young people aged 0-24 in high-income countries and the seventh-highest contributor to DALYs in low- and middle-income countries. Globally, mental illnesses account for a quarter of all years lived with disability (YLDs) in children and youth aged 0-24 [2].

Despite this heavy burden, many youths with mental health problems remain untreated or face delayed detection, long waitlists and multiple help-seeking contacts before obtaining appropriate care $[1,3]$. Such complex 'pathways to care' delay treatment. For youths (typically understood as individuals who are within the critical development juncture between childhood and adulthood, i.e., aged between 11 and 
25-30 years old $[4,5])$, longer durations of untreated illness can have grave impacts on the foundations of their adult lives and can be associated with worse clinical outcomes [6, 7].

Pathways to care-defined as the "sequence of contacts with individuals and organizations prompted by the distressed person's efforts, and those of his or her significant others to seek help, as well as the help that is supplied in response to such efforts" [8] — have been garnering research attention for several years. In the early 1990s, a multinational study by the World Health Organization (WHO) [9] showed that pathways to mental healthcare varied substantially depending on context and resource availability. In regions with access to relatively well-developed mental health services, patients experienced more direct routes from the community to specialized care. However, in areas with few services, patients experienced a wide variety of pathways that often included traditional or faith healers.

In the field of first-episode psychosis, concern with the adverse consequences of delayed treatment [10] has spurred numerous investigations of pathways to care and barriers to accessing specialized services [11]. In addition to primary care providers and mental health services, help-seeking pathways for psychotic disorders involve diverse contacts like emergency rooms (ERs), social services, the criminal justice system, school counsellors, and religious agencies. Pathways to psychosis services have been known to be influenced by several sociodemographic factors, including gender, age, ethnicity, and socioeconomic status [12]. However, these findings have been inconsistent and their implications for policy and service delivery difficult to assess.

Sequences of healthcare contacts do not occur randomly [8], but are influenced by multiple intersecting individual, social, cultural, and systemic factors. Studying pathways to care allows us to identify the loci of barriers and delays to treatment; and key agents in the help-seeking process, including individuals in distress, family/carers, informal contacts (e.g., teachers, employers, web resources, etc.), and formal health services. Such knowledge is crucial for providing timely access to services.

New youth mental health initiatives [13], including in but not limited to Australia, Canada, Ireland and the United Kingdom, are striving to make appropriate services accessible early in the course of mental illnesses to mitigate their short- and long-term negative consequences. It has been argued that extant conventional mental health systems are neither youth-friendly nor sufficiently accessible. Young people and their families have described mental health helpseeking as a long, painful, and complicated journey. Though they represent the peak incidence of mental health problems, youths are frequently the least likely to use mental health services [14] and often receive help only when their problems become crises. Their help-seeking efforts may also be impeded by repeated evaluations and difficult transitions, especially between child and adult services [15].

Although literature reviews on pathways to care have been conducted in the field of psychosis $[11,16]$ and across adult mental health disorders [17], evidence on the different trajectories youths follow to obtain mental healthcare has yet to be synthesized. Such a synthesis is essential if efforts to transform youth mental healthcare $[13,18]$ are to achieve their ends. Our objective was therefore to conduct a systematic review of literature on young people's pathways to care for a range of mental health problems.

\section{Methodology}

The protocol for this systematic review was developed in accordance with the Preferred Reporting Items for Systematic reviews and Meta-Analyses [19] (PRISMA) and was registered at the PROSPERO Centre for Reviews and Dissemination (ID: 42016039208) in June 2016.

\section{Search strategy}

Search terms were generated by consulting 20 experts in youth mental health across disorders, and a university librarian. We included search terms related to pathways to care; service utilization; help-seeking; mental disorders; and delays to treatment (see online supplementary material for search strategy).

Relevant studies were identified through searching five electronic databases: MEDLINE (1946 onward), Embase (1947 onward), PsycINFO (1967 onward), HealthSTAR (1966 onward) and CINAHL (1937 onward). Articles were further identified using backward and forward citation mapping of selected articles using Web of Science, and hand searches of journals that had previously published material on pathways $(n=4)$. The electronic search was conducted in July 2016 and updated in March 2018.

\section{Selection of relevant studies}

Two experts independently screened titles, abstracts, and keywords and resolved disagreements by consensus. Articles were included if they were peer-reviewed; were written in English or French; and reported quantitative findings. To be selected, studies had to focus on youths' individual trajectories to seeking or receiving treatment for mental health or substance use at any establishment, regardless of the presence or absence of a formal diagnosis. The mean age of study participants had to be between 11 and 30 years (so as to include the largest possible range of definitions of 'youth' used in pertinent literature). Alternatively, at least $50 \%$ of a study's sample had to be within that age range. We excluded 
studies of youths with chronic physical health conditions or a primary diagnosis of intellectual disability. Full texts were obtained for all potentially relevant studies. Two reviewers independently screened the full text of each article to check whether it met inclusion criteria.

The authors of six studies were contacted for additional information to determine their eligibility. Of these, three authors responded and provided data that had not appeared in the original studies, which were then included in our review.

\section{Data extraction}

A data extraction sheet was created and refined following pilot testing on ten randomly selected included studies. Two reviewers independently extracted and compared data from all included studies and resolved disagreements by discussion.

We extracted data on participant demographics, study design, instruments used, study setting, healthcare context, pathways to care, and measures of treatment delay. If needed, authors were contacted for clarifications or missing information.

The two reviewers also independently ascertained the quality of each included study using a rating scale adapted from the Newcastle-Ottawa Quality Assessment tool [20], which had been used in a systematic review on pathways to care in first-episode psychosis [21] (see online supplementary material).

\section{Results}

The electronic search yielded 17,381 publications, including 1454 from the March 2018 search update. Hand searching yielded another 45 articles. After duplicates were removed, 11,524 studies remained. Initial title and abstract screening identified 845 potentially relevant studies for full-text screening. Of these, 45 studies fulfilled the inclusion criteria (see Fig. 1). The main reasons for exclusion were misalignment of studies' objectives with those of this review, study methodology, language, and participants' age ranges. Five studies were excluded post hoc because their participants' age ranges could not be established $(n=3)$, or for involving the same participants as other included publications $(n=2)$.

\section{Study characteristics and settings}

The characteristics of included studies are summarized in Table 1 . The studies were conducted across a wide range of countries $(n=26)$. Their sample sizes ranged from 15 to 1266 (mean =203). Twenty-six studies were conducted in services catering to persons with first-episode psychosis.

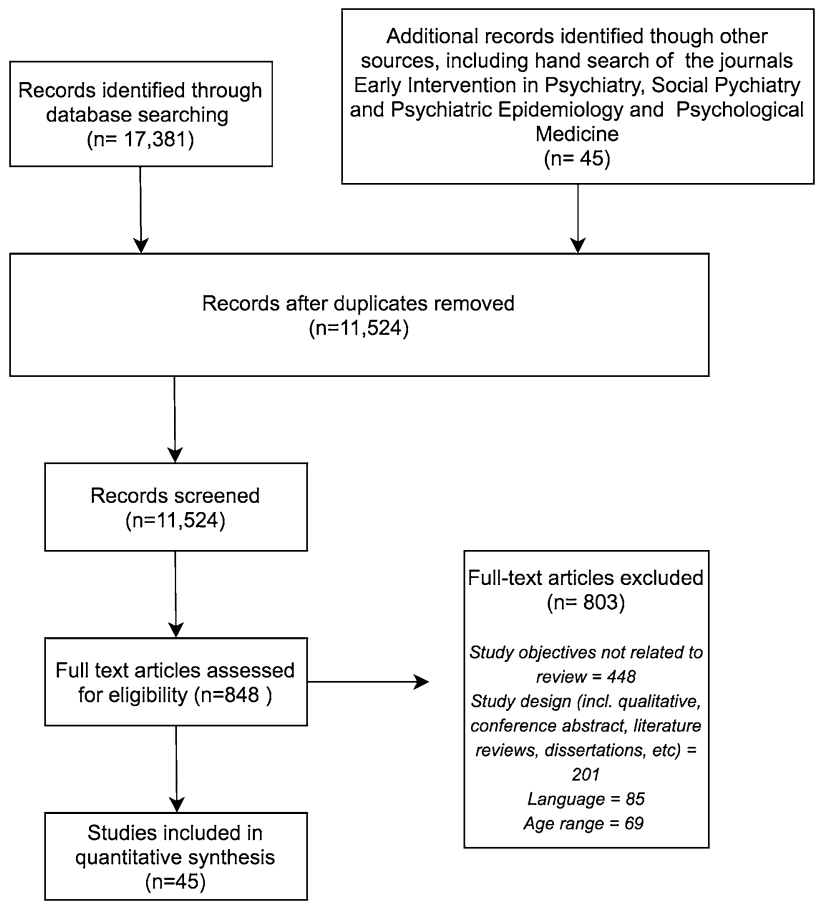

Fig. 1 PRISMA flow chart of included studies

Other study sites were general psychiatric inpatient $(n=3)$ and outpatient units $(n=9)$; and specialized services for youths with anorexia $(n=1)$ and those at risk for psychosis $(n=6)$.

\section{Healthcare system and organizational contexts}

We extracted information about the healthcare system in which each study was conducted (Table 2). Many studies described organizational features, including available healthcare tiers (e.g., public/private) and local practices (e.g., preference for traditional healers). Fourteen studies reported allowing open referrals, wherein direct referrals to the services were possible. Two studies described a gatekeeper system where referrals from primary care were required to access mental healthcare. All other studies did not specify their settings' referral systems.

\section{Instruments and data sources}

Studies differed in the instruments used to ascertain pathways to care. The majority had developed their own interview guide or questionnaire $(n=22)$ but provided limited to no information on the methodology used to develop the measures or their psychometrics. Semi-structured interviewbased instruments included the WHO Encounter Form [9] $(n=14)$; the Circumstances of Onset and Relapse Schedule [66] for early psychosis $(n=4)$; the Pathways to Care 


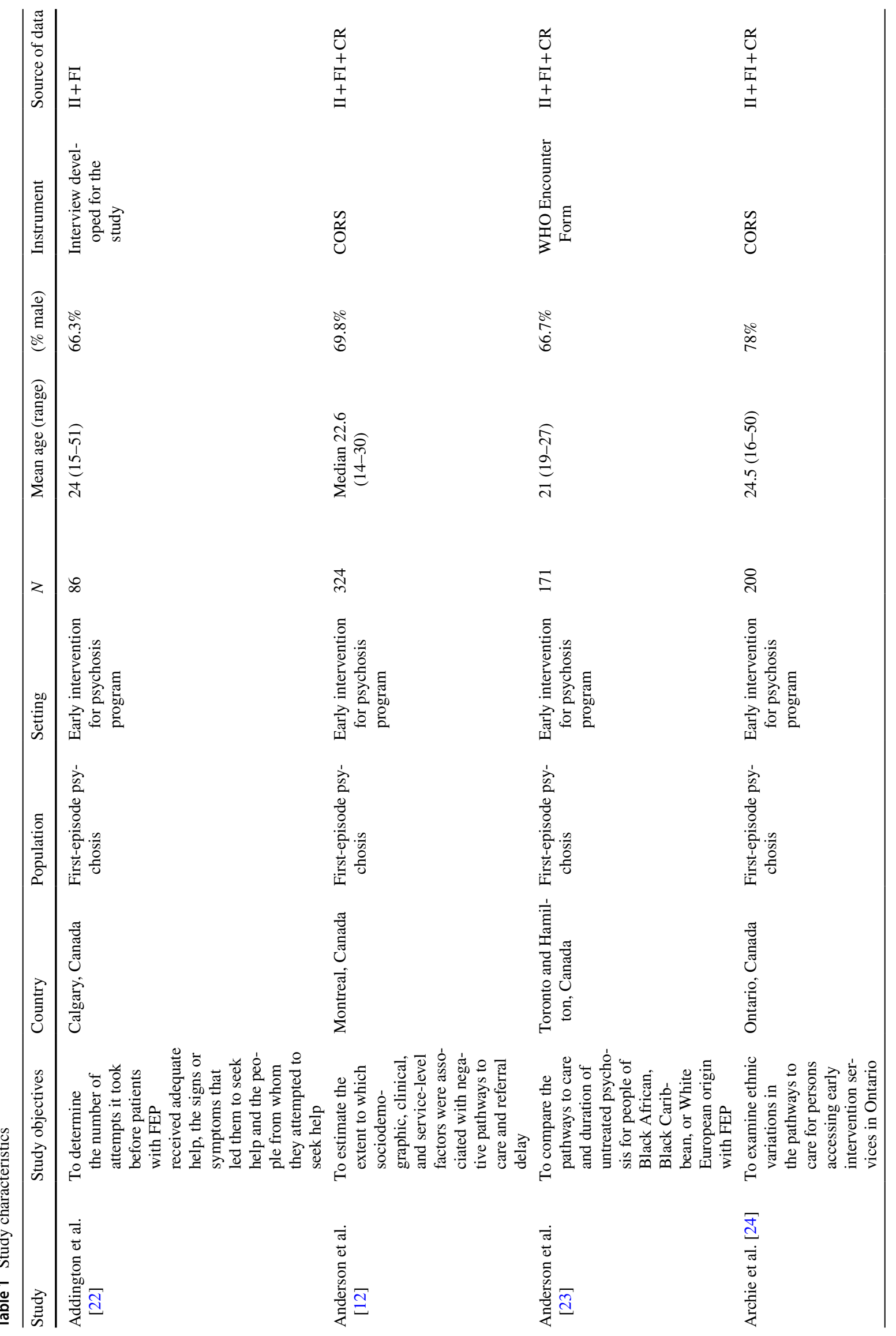




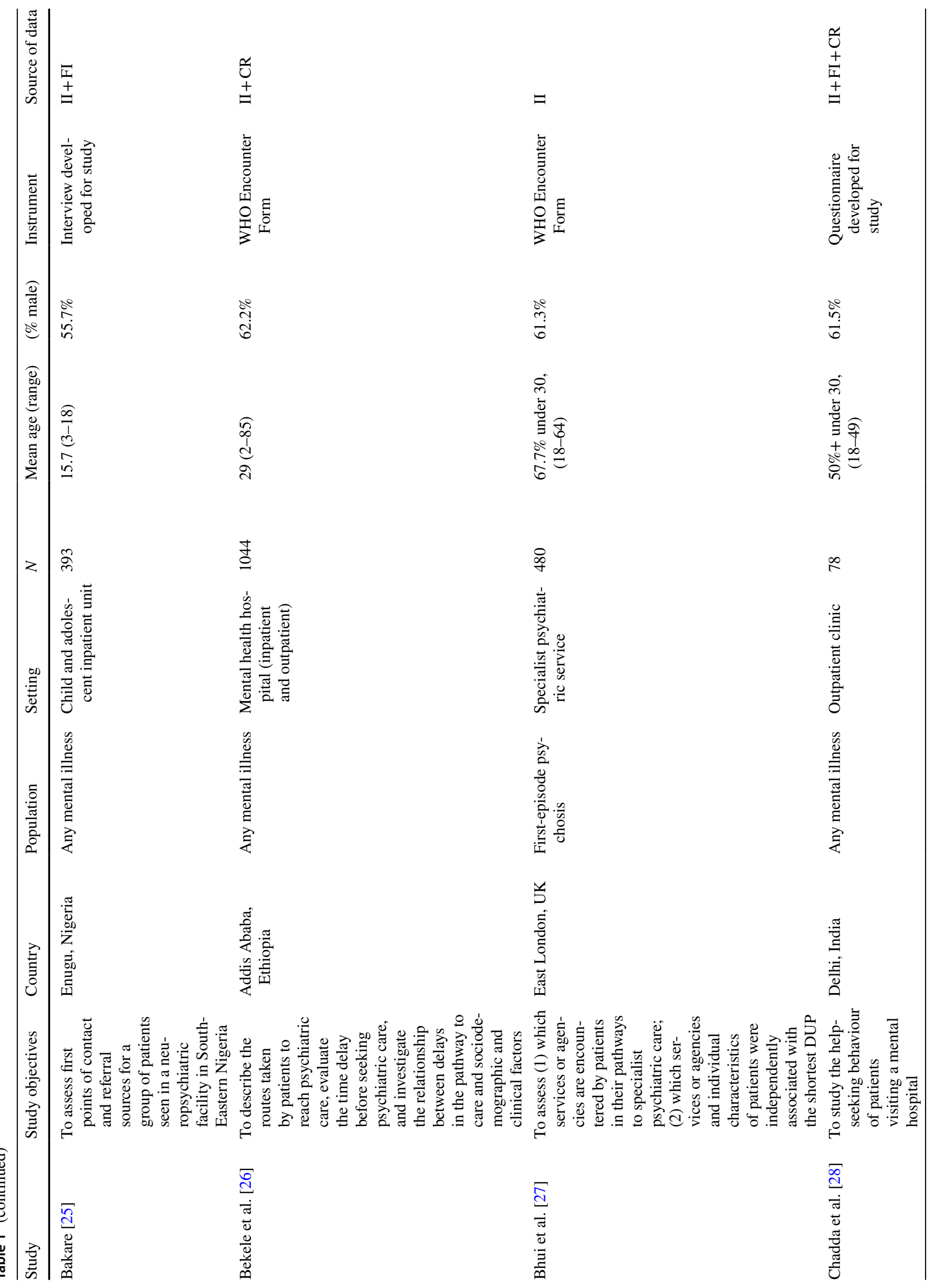




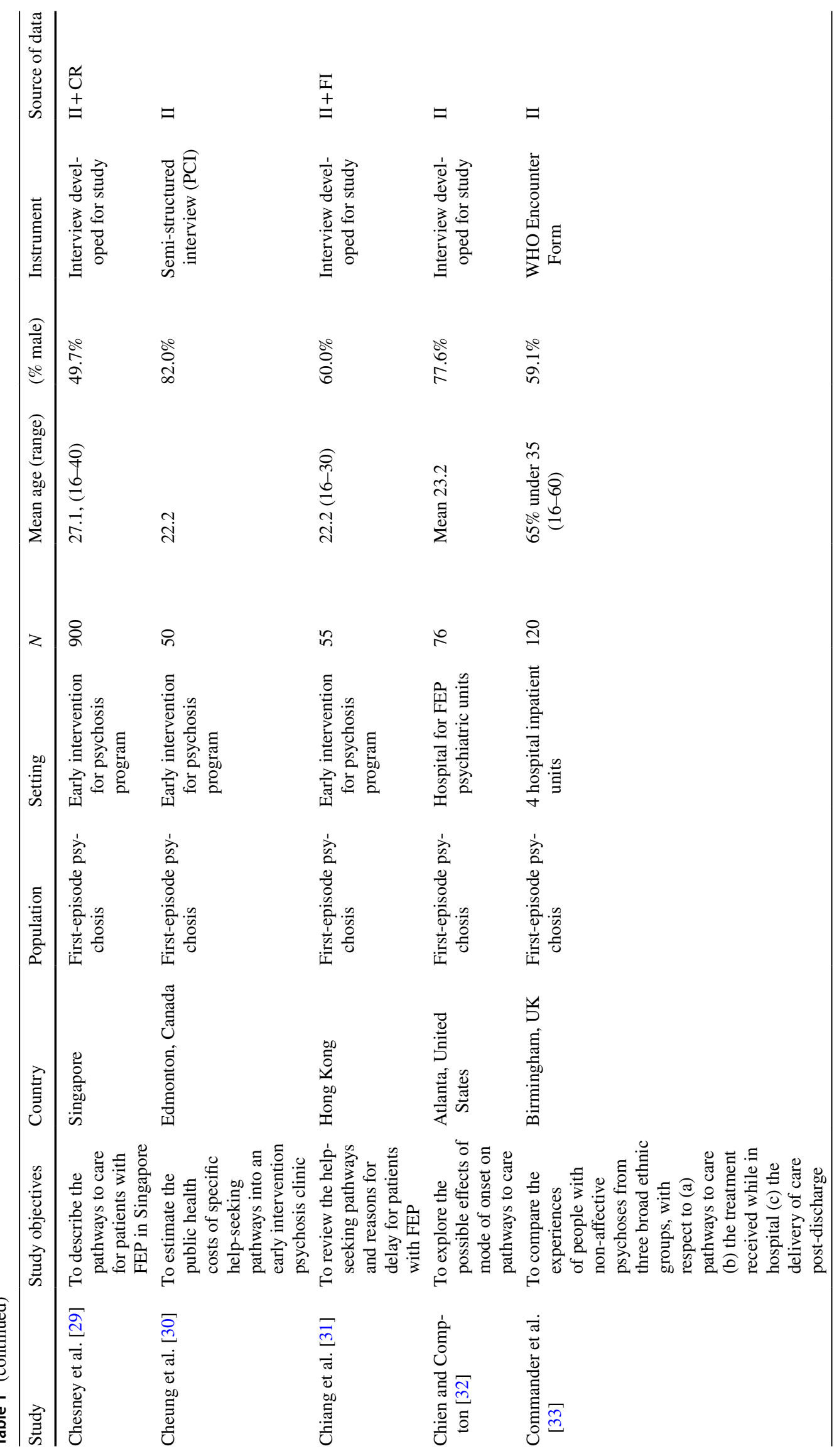




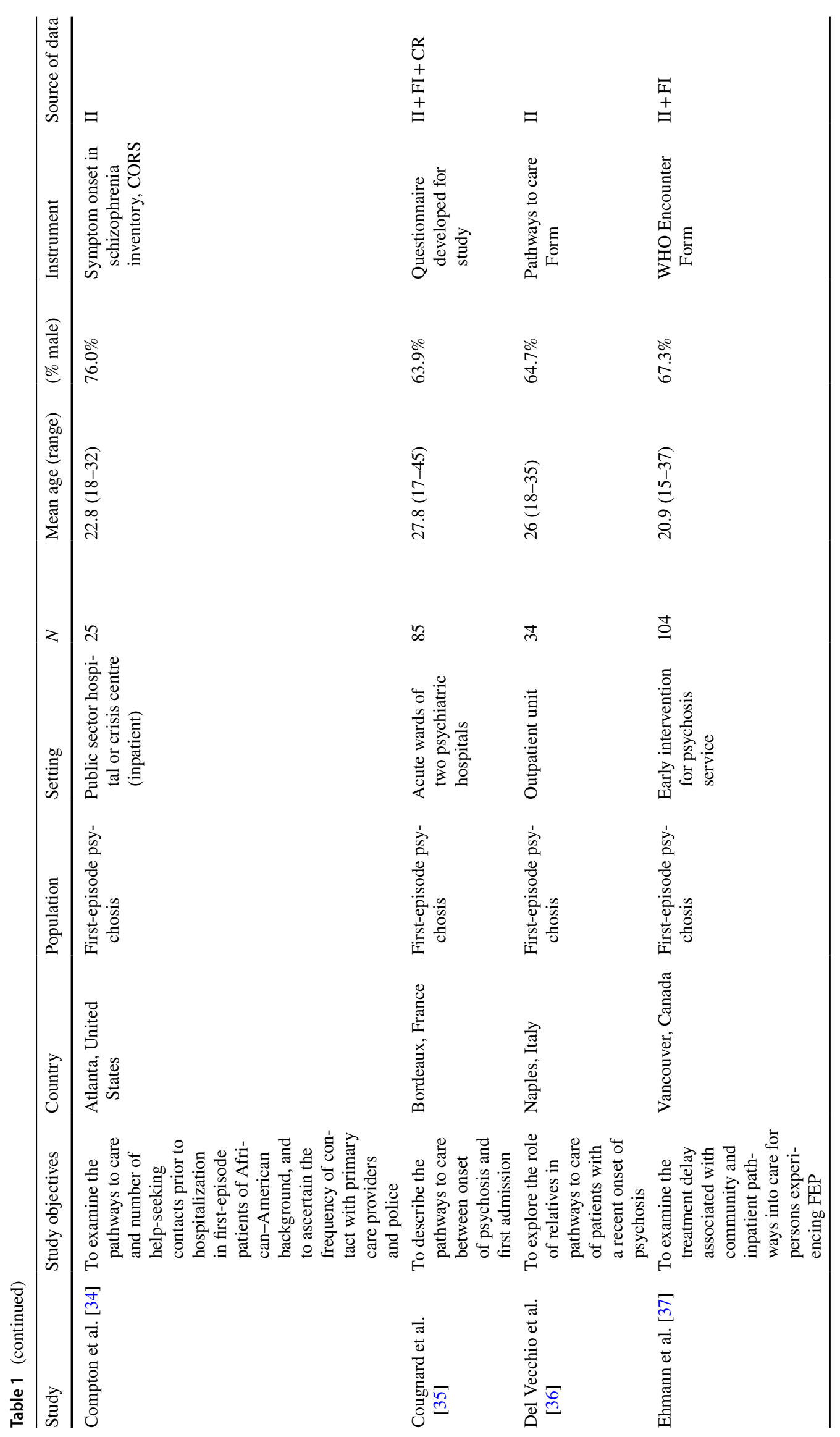




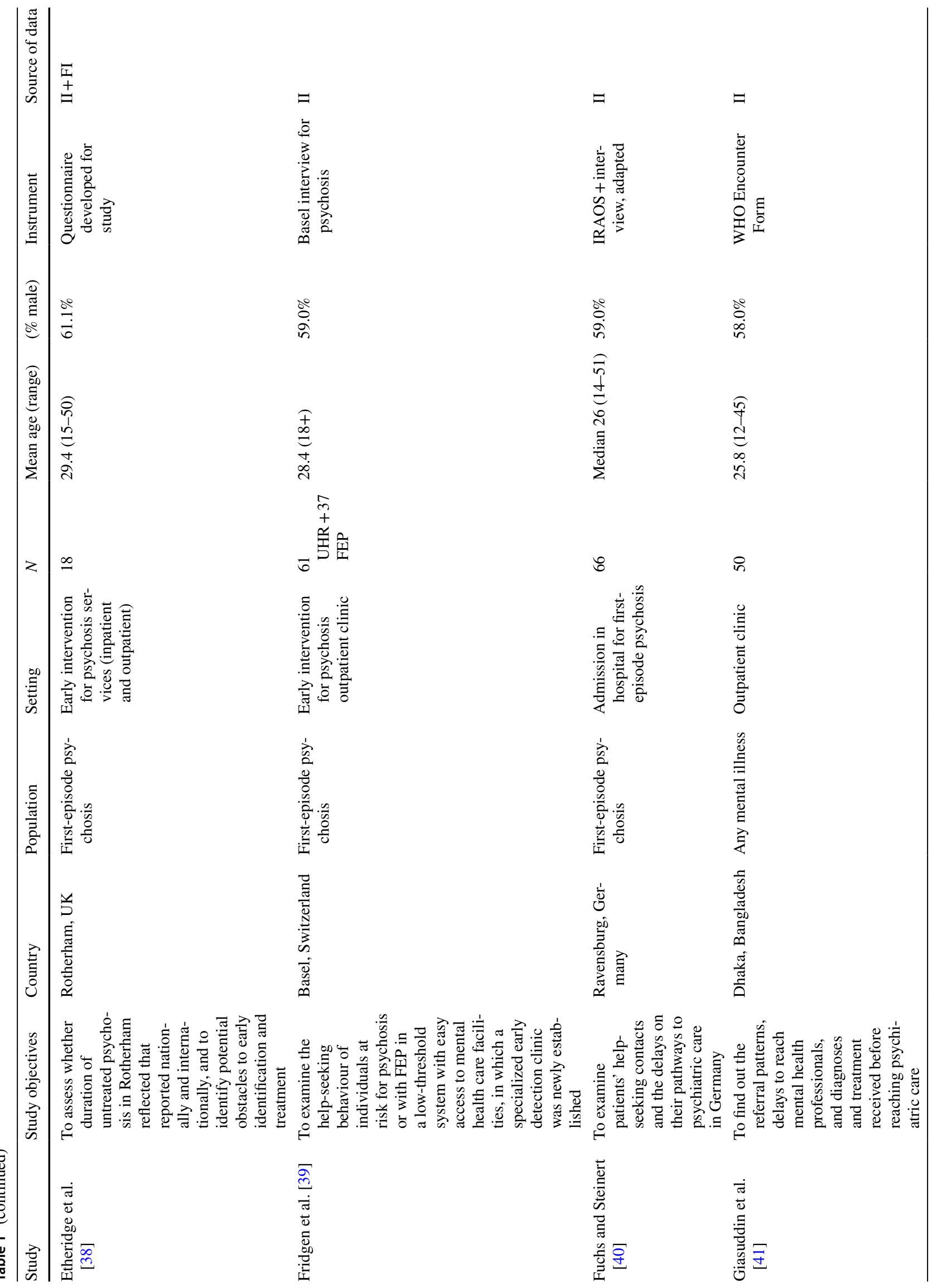




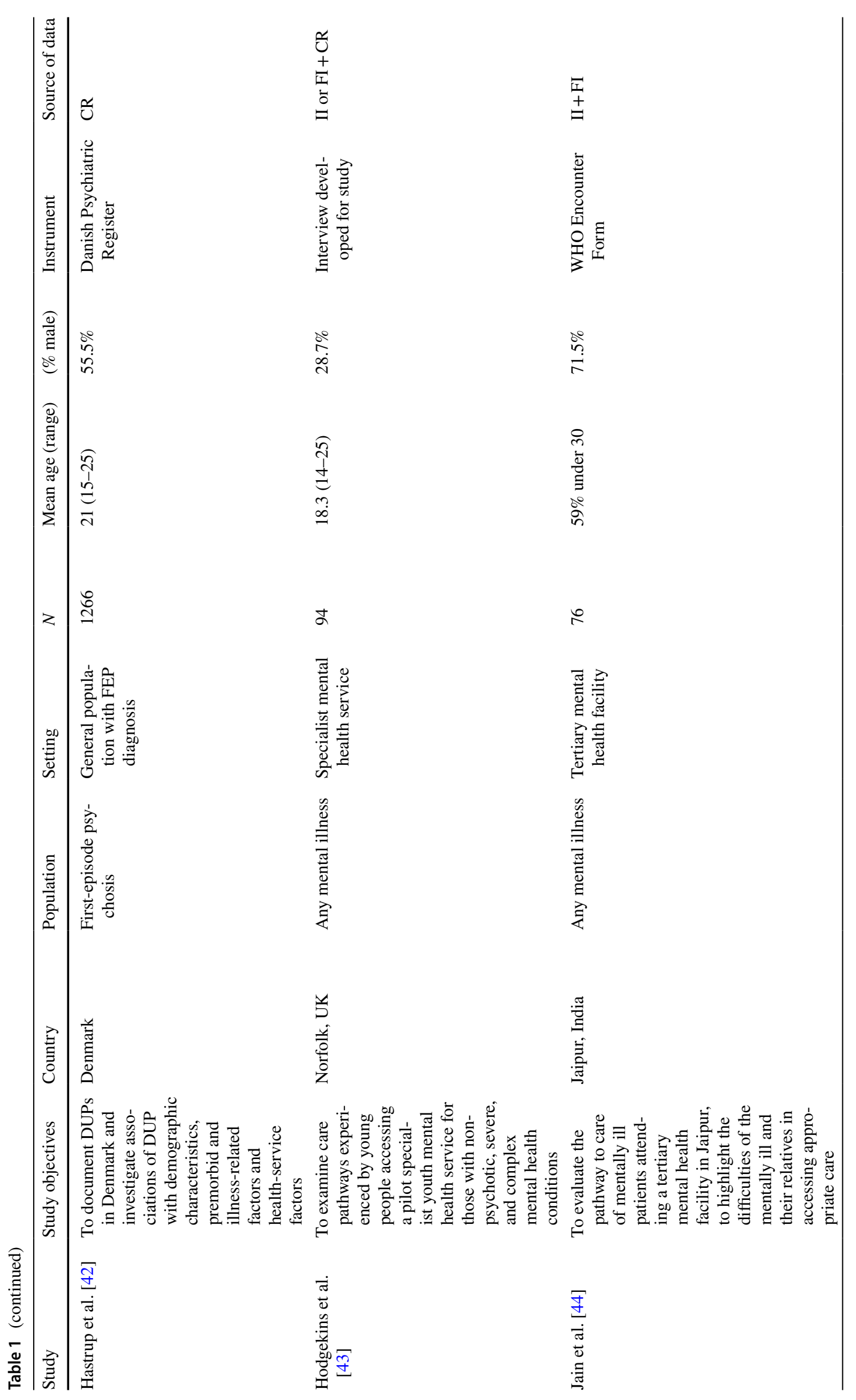




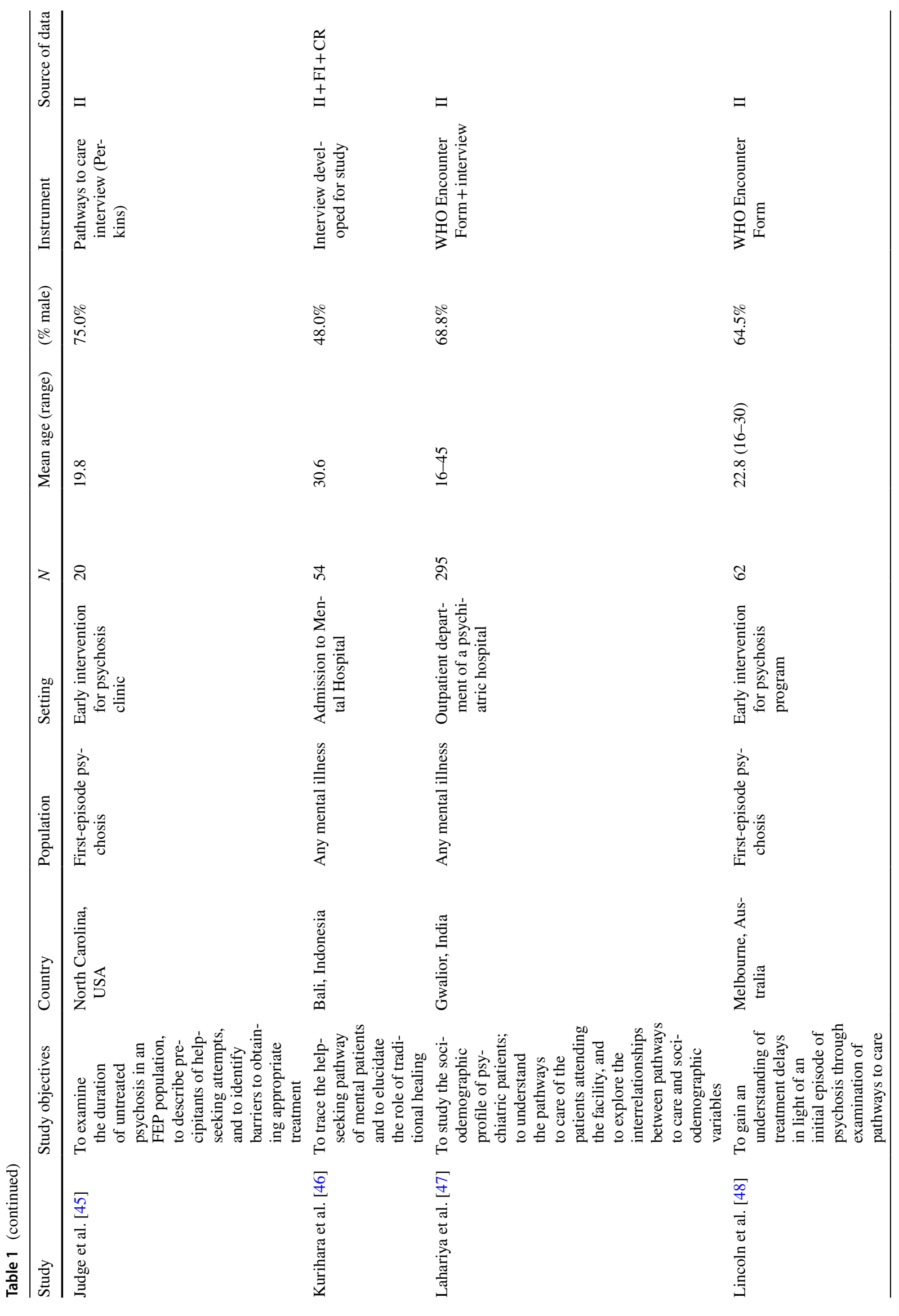




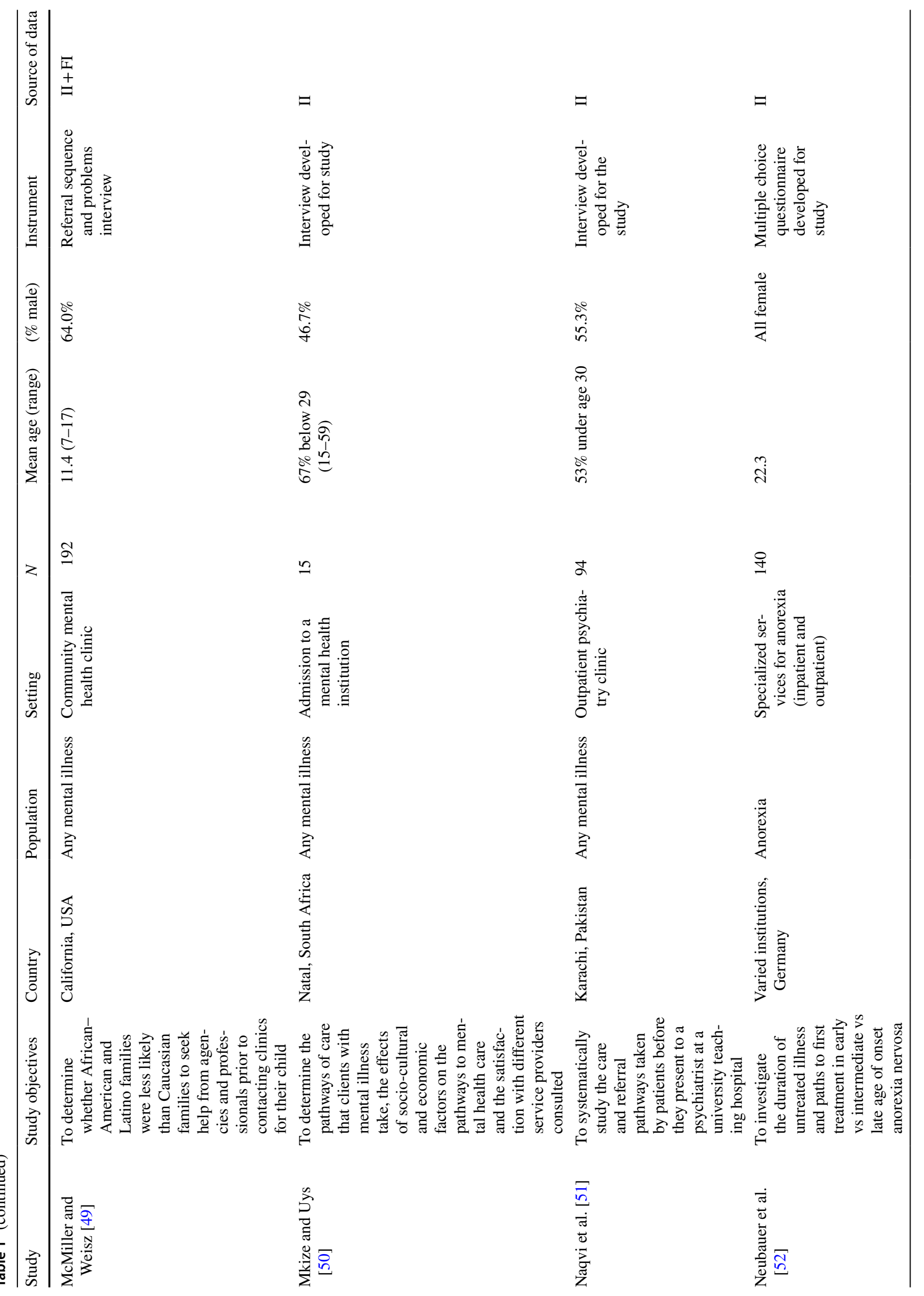




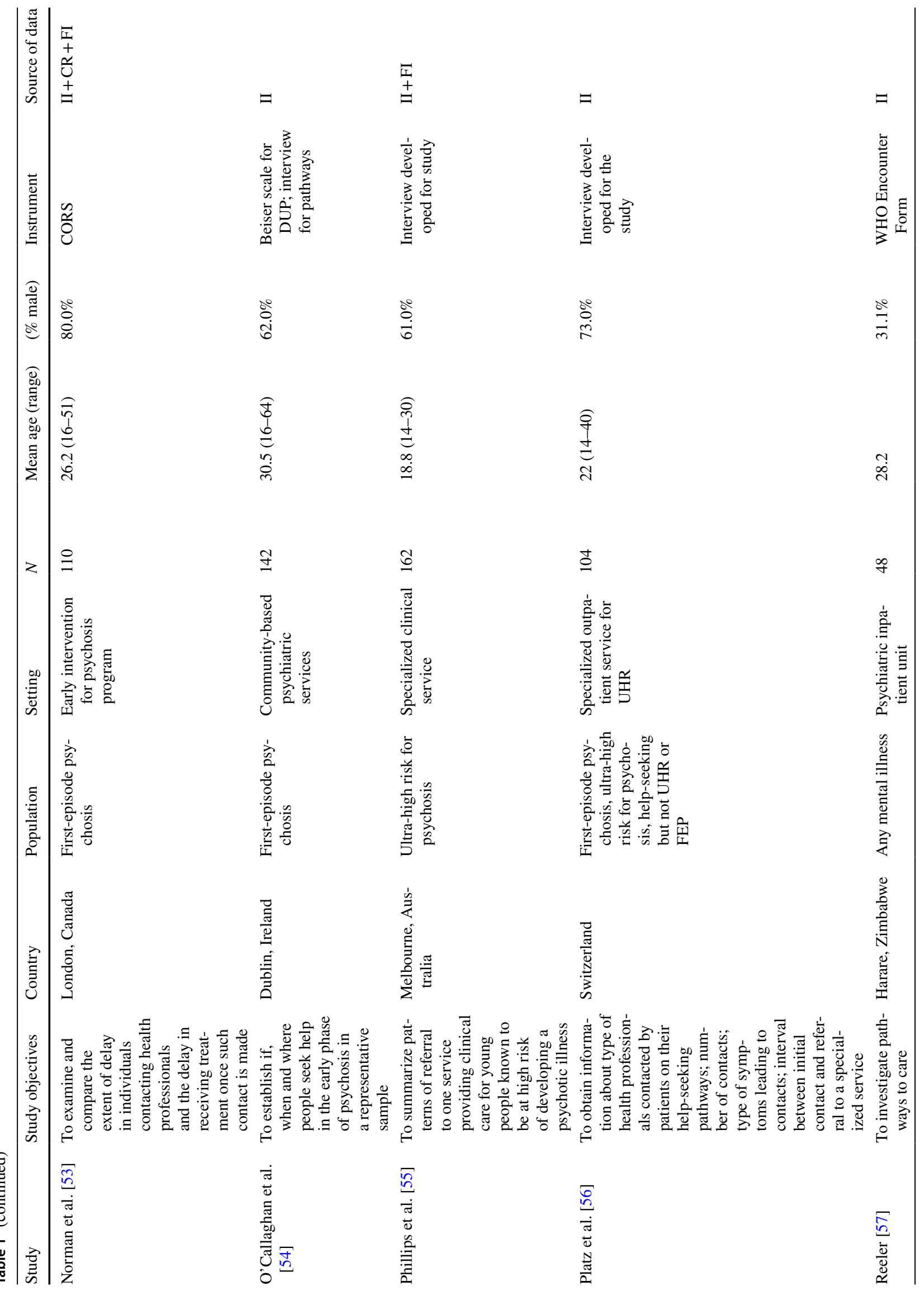




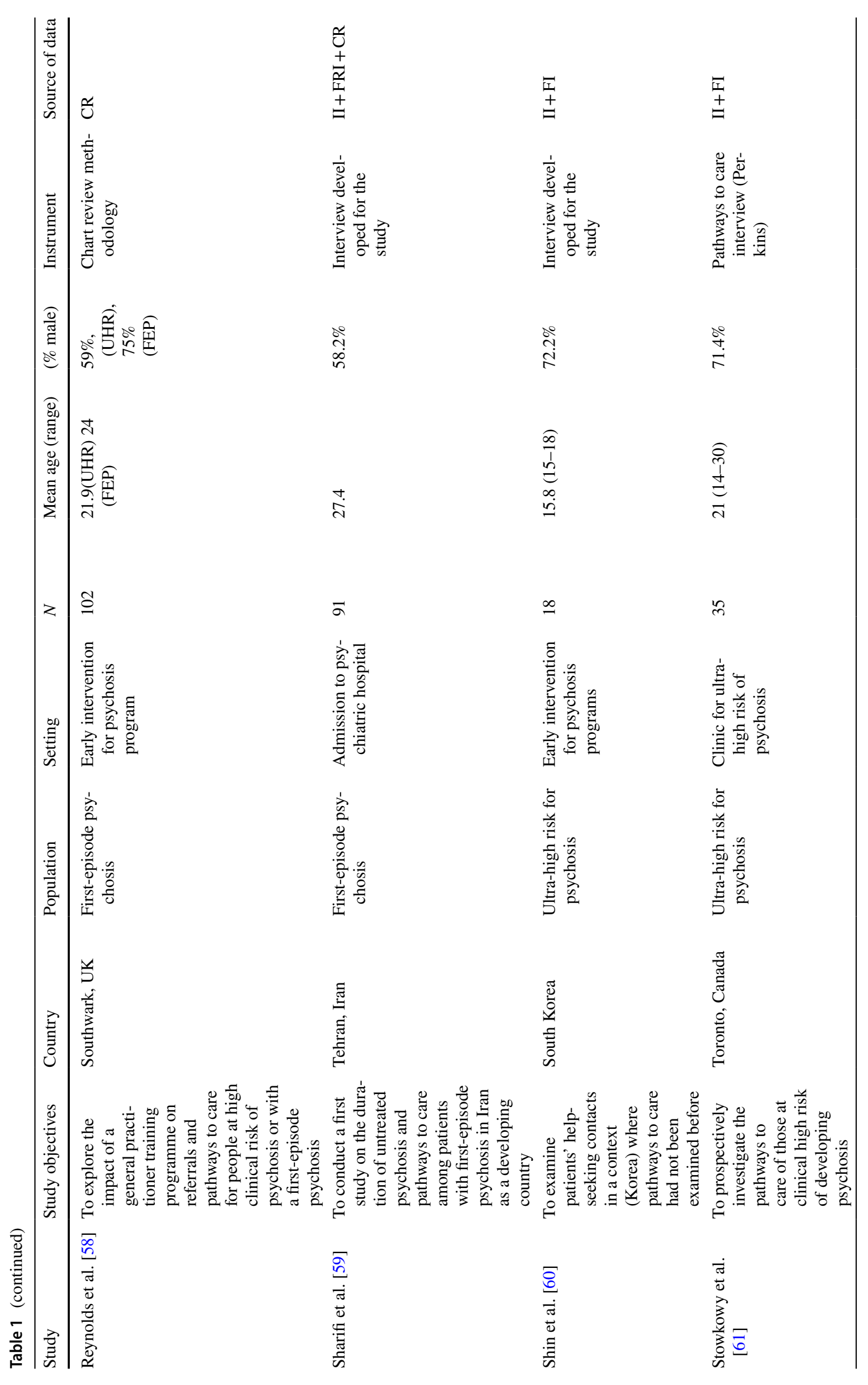




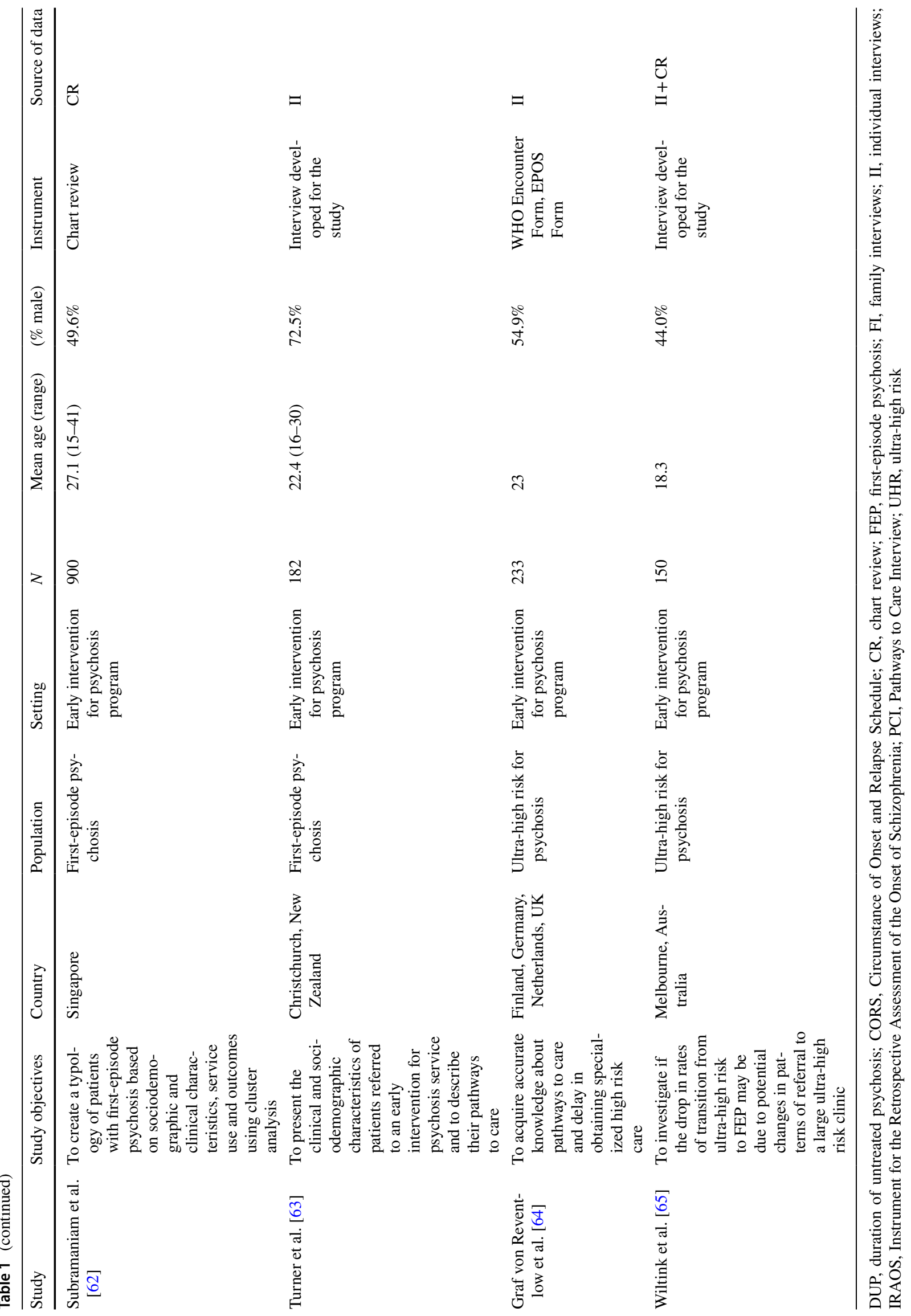




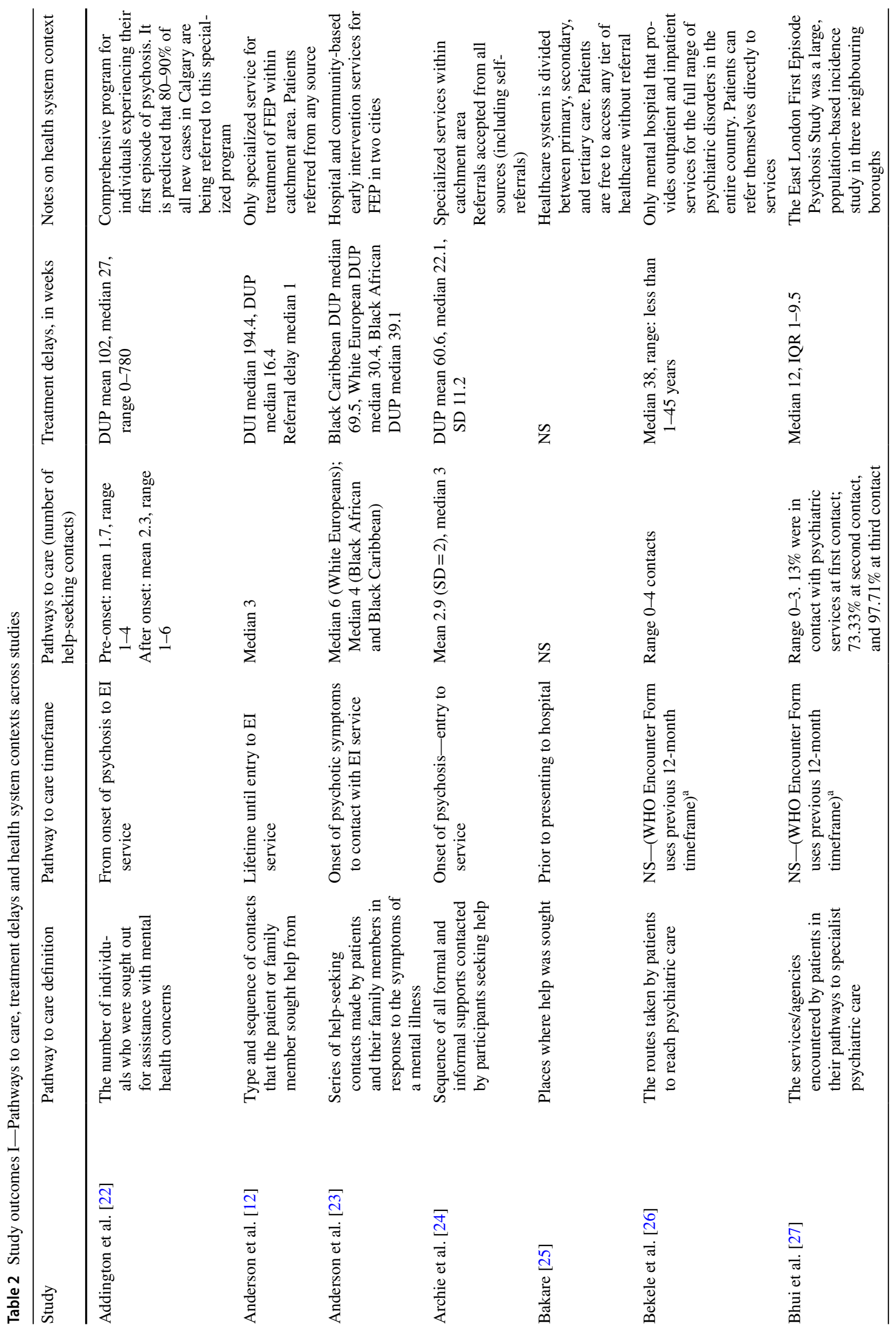




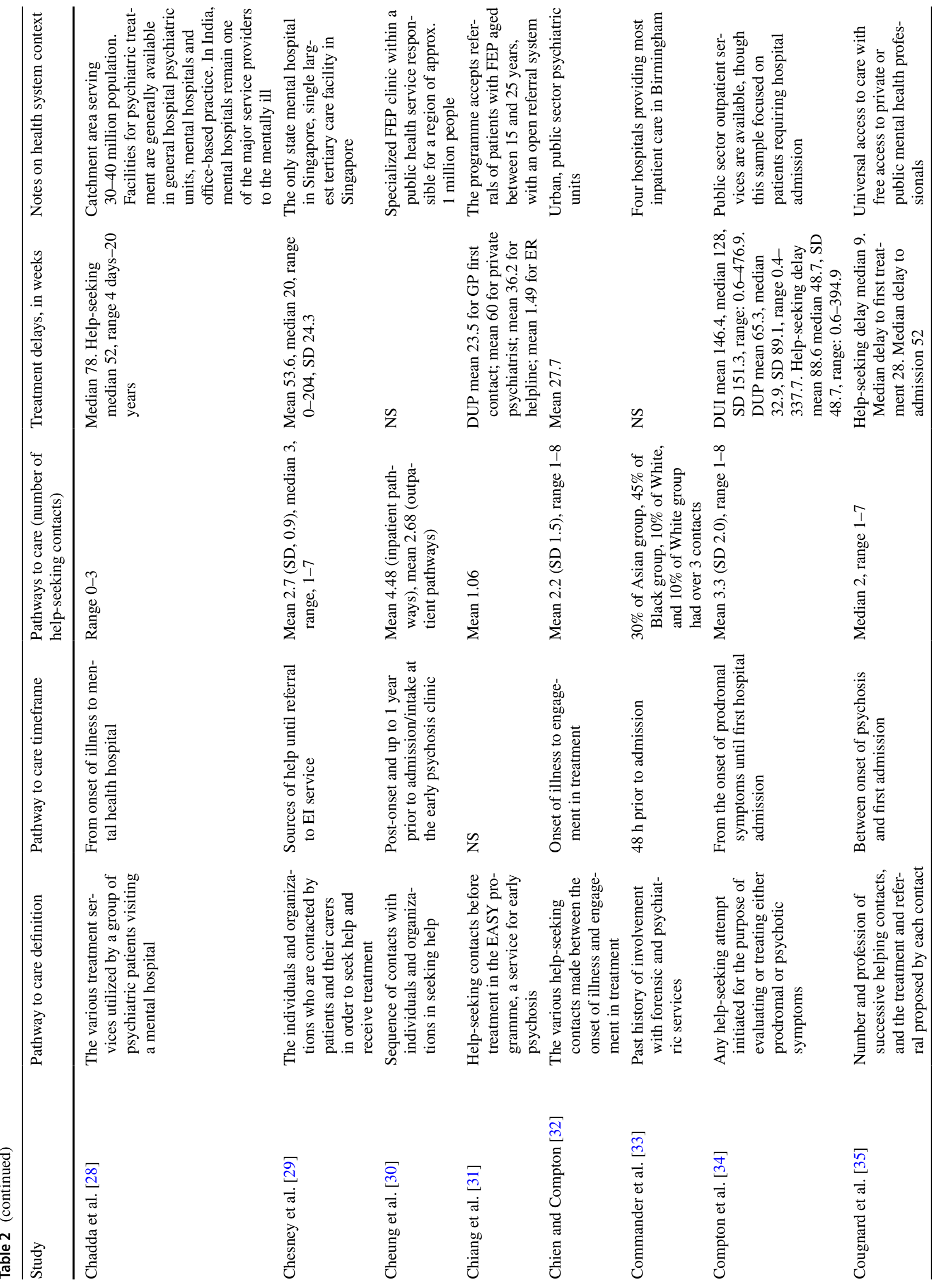




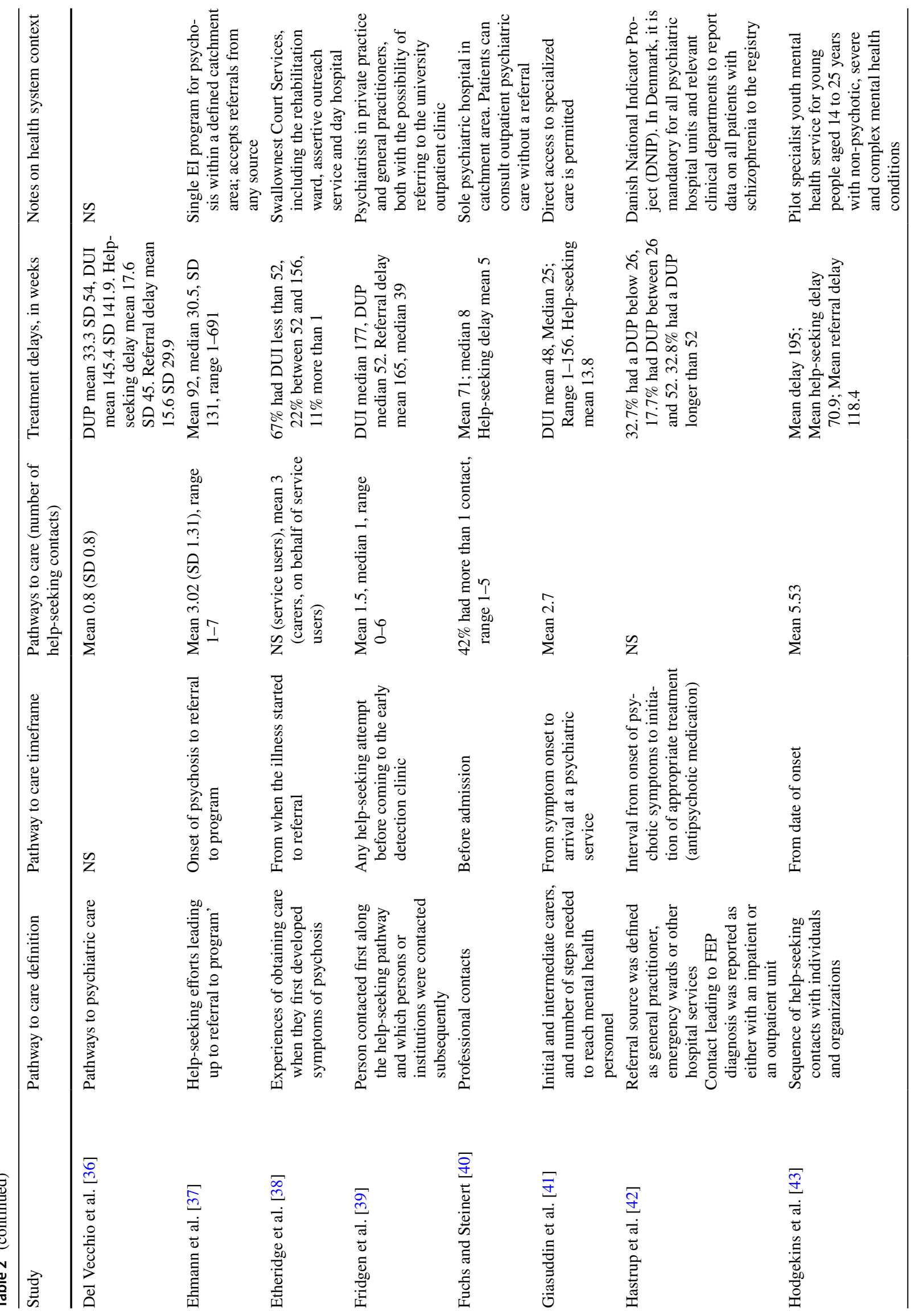




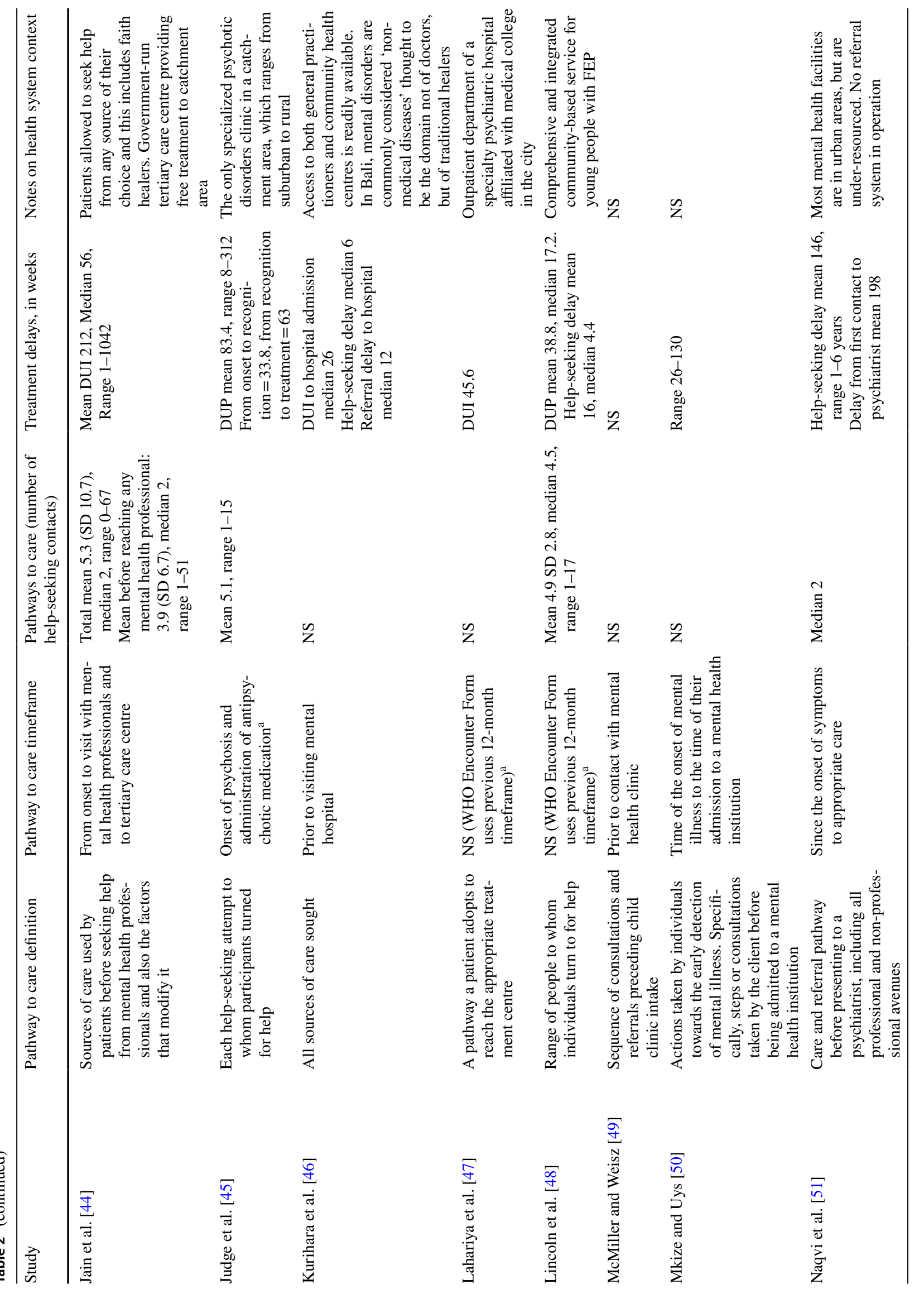




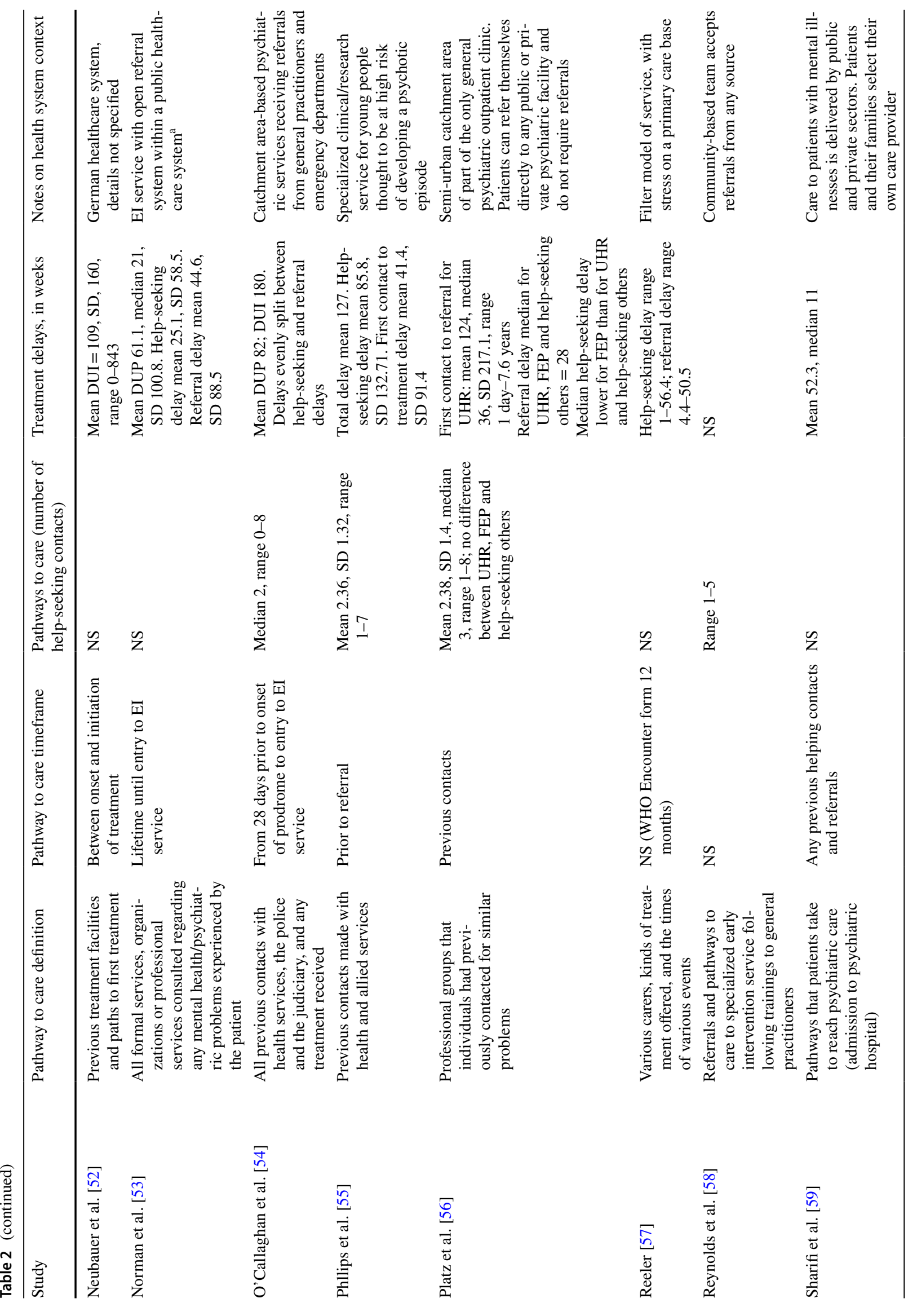




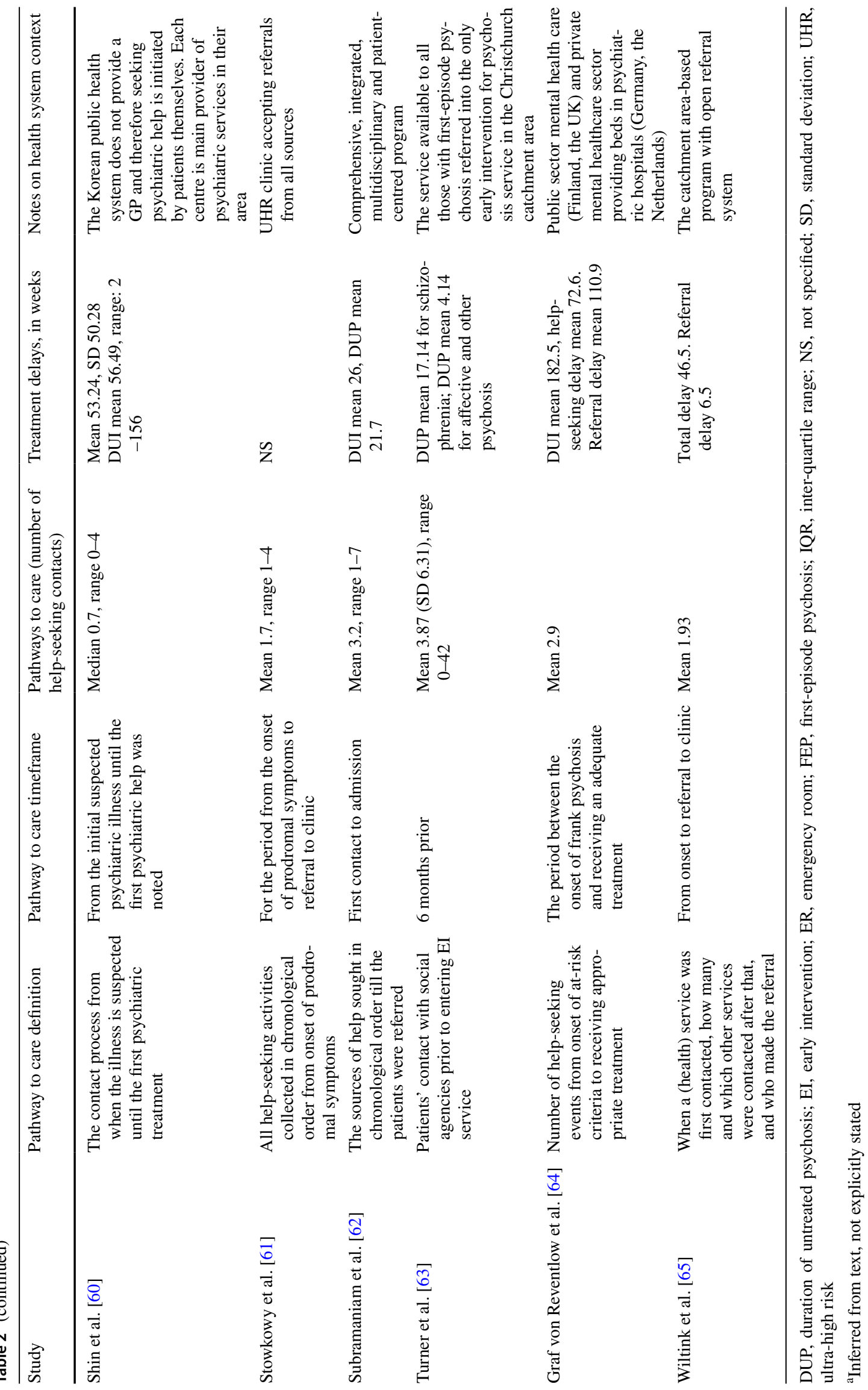


Schedule [67] $(n=3)$; and the Basel Screening Instrument for Psychosis [68] $(n=1)$. One study used the structured Referral Sequence and Problem Interview [49].

Irrespective of the instruments used, most studies collected and corroborated information from multiple sources $(n=27)$. In these cases, individual interviews were supplemented by family/carer interviews and/or chart review. Some studies relied on a single data source-patient interviews $(n=16)$ or chart information $(n=2)$. One study used national registry data, which included healthcare contacts and durations of untreated illness.

\section{Timeframes}

Timeframes for delimiting pathways to care, i.e., the start and endpoints of journey into care, differed widely across studies. Startpoints included the onset of symptoms or initial suspected illness $(n=22) ; 6$ months preceding entry $(n=1)$; lifetime $(n=4) ; 28$ days preceding prodromal symptom onset $(n=1) ; 48 \mathrm{~h}$ prior to admission $(n=1)$; and first contact with health services $(n=1)$.

Endpoints included entry or referral to a specialized service $(n=13)$; admission to hospital $(n=8)$; initiation of care $(n=7)$; and entry to a general psychiatric service $(n=5)$. For studies that did not specify a timeframe but used the WHO Encounter Form $(n=5)$, we assumed that instrument's stated timeframe of 12 months preceding the interview (see Table 2). Other studies did not specify clear start $(n=10)$ or endpoints $(n=7)$.

\section{Pathways to care}

The focus of this review was on articles that examined individuals' pathways to care (i.e., sequence or number of helpseeking contacts). Outcome measures included descriptions of full trajectories, or first and last contacts before a specific endpoint. Considered clinically relevant, first and last contacts are often described in pathways to care studies [16].

Thirty-five studies described full pathways to care sequences, including the total number and types of contacts in individual participants' pathways to care. Seven studies described the most common pathway contacts for their sample, in addition to common first and last contacts. Three studies described the most common overall and first contacts along participants' pathways to care (see Table 3 ).

\section{Overall pathways}

Twenty-eight studies reported the number of contacts before receiving specific services, which ranged from 0 to 15 contacts per participant (with a pooled mean across studies of
2.9 contacts). One study [43] dichotomized pathways into 'short' (three or fewer services before referral) and 'long' (four or more services). Its authors noted that the number of contacts did not always indicate pathway complexity or length of delay. For example, a pathway with many contacts could reflect appropriate referrals as mental health problems progressed, whereas shorter pathways could reflect repeated contacts with specific services or concurrent use of different services before an appropriate referral.

\section{Key pathway agents}

Contacts involved in young people's pathways to mental healthcare were varied and included medical professionals (general practitioners, psychiatrists); non-medical professionals (psychologists, social workers, counsellors, school teachers, rural healthcare workers); informal sources of help (family, friends, employers, colleagues); healthcare institutions (emergency services, inpatient units, walk-in clinics); criminal or justice system (police, prisons, lawyers, courts); traditional or faith-based healers (prayer houses, priests, herbalists, clergy); and technology-enabled contacts (websites, helplines, crisis lines) (Table 3 ).

\section{First contact}

Twenty-nine studies reported the first contact along the pathway to care. In order of frequency, young people's first help-seeking contacts were general practitioners (14/29); psychiatrists or specialized services $(5 / 29)$; faith or traditional healers (4/29); ERs/inpatient units (3/29); family or friends (2/29) and social workers (1/29). General practitioners were among the top three most frequent first sources of help in 24 of 29 studies.

\section{Referral sources}

Studies of pathways to care often describe their referral source as the 'successful contact', i.e., the contact that resulted in an individual obtaining the service in question. This successful contact is also referred to in some studies as the "last" contact. Twenty-two studies examined referral sources. Of these, eight described the ER/inpatient unit as the most common 'successful' referral source. Self-referrals (i.e., referrals made by youths themselves, or by family/carers on their behalf) were the most frequent referral source in six studies. Other prominent referral sources included general practitioners, general hospitals, helplines, and outpatient units. 


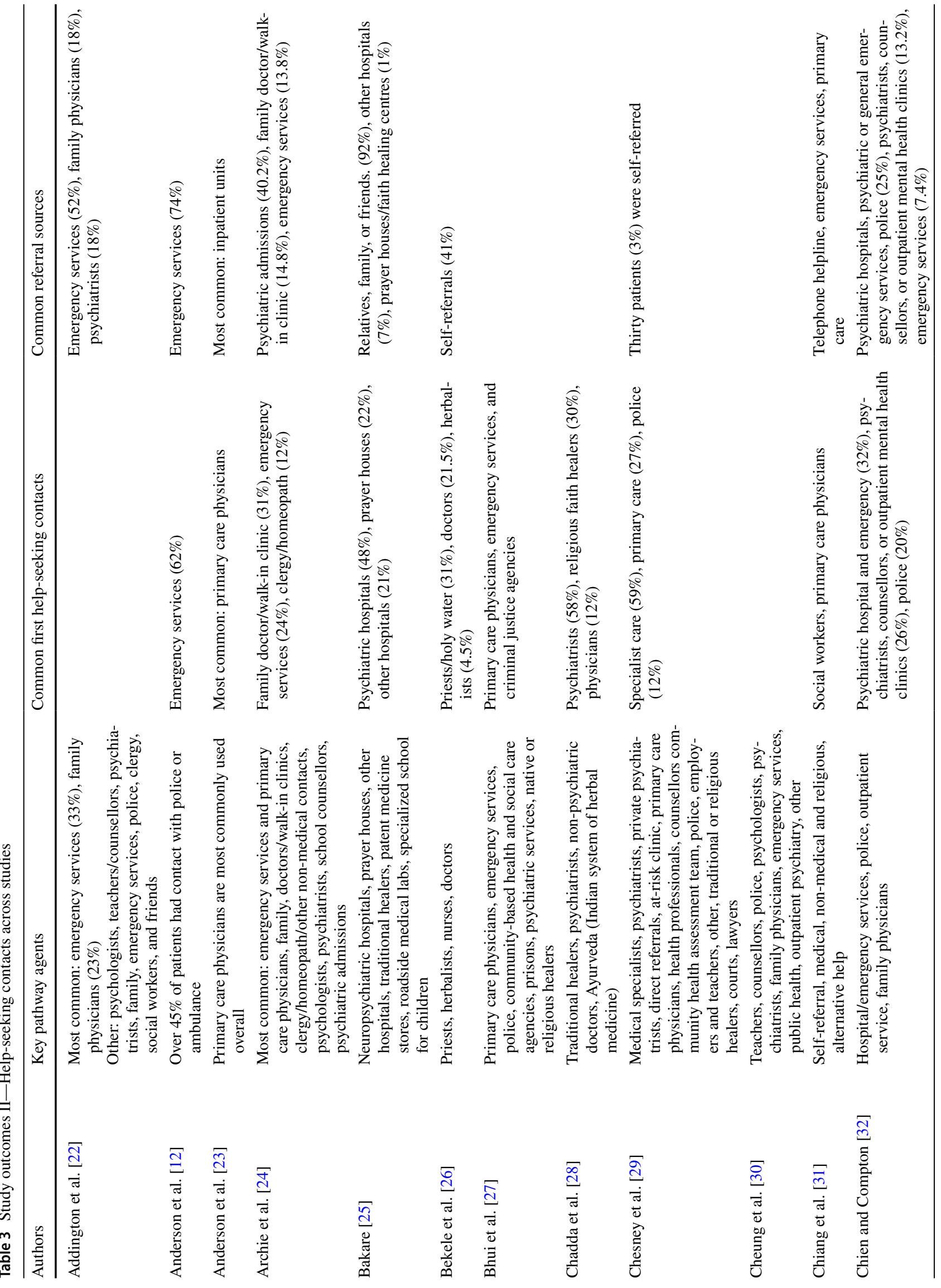




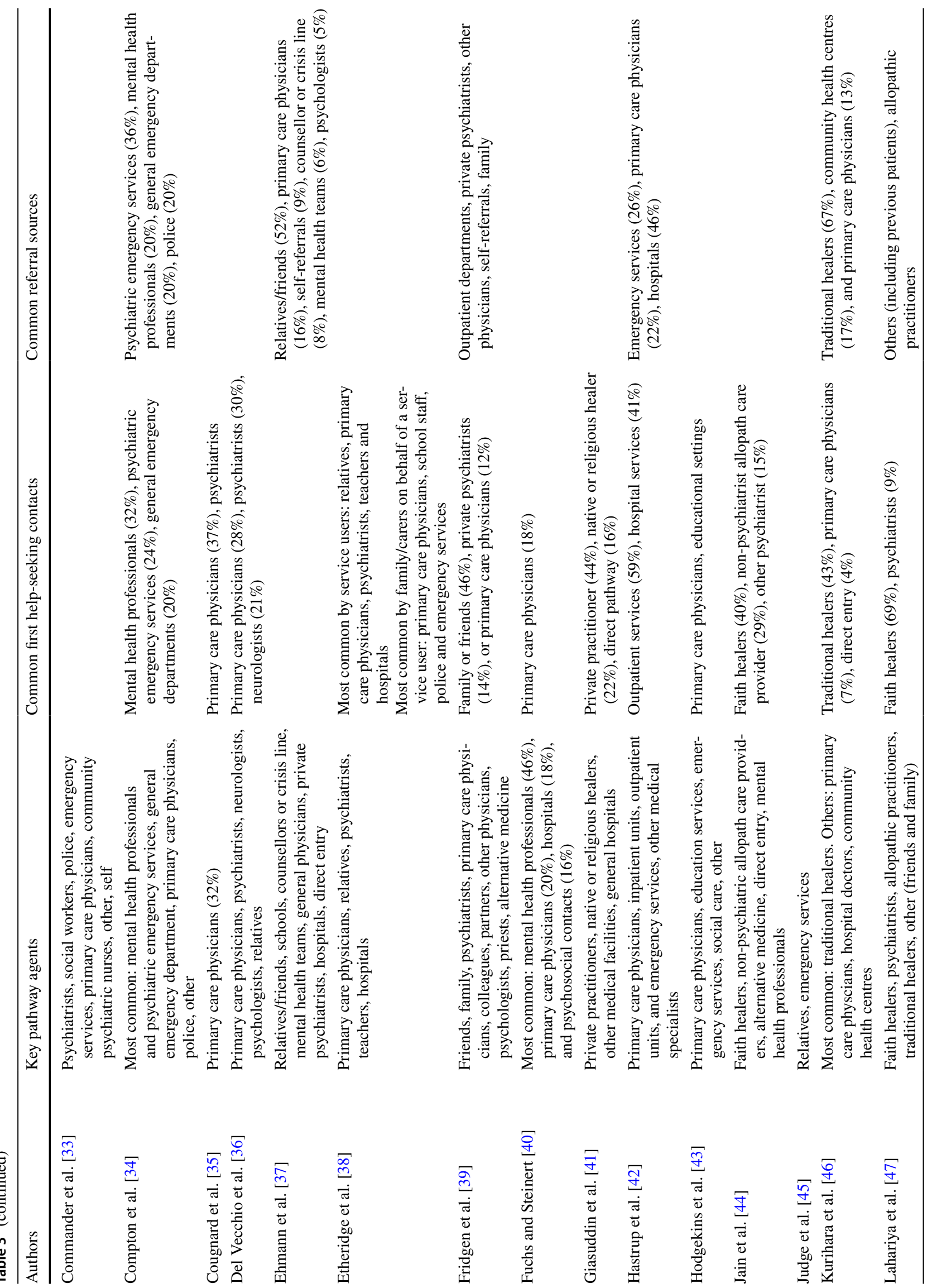




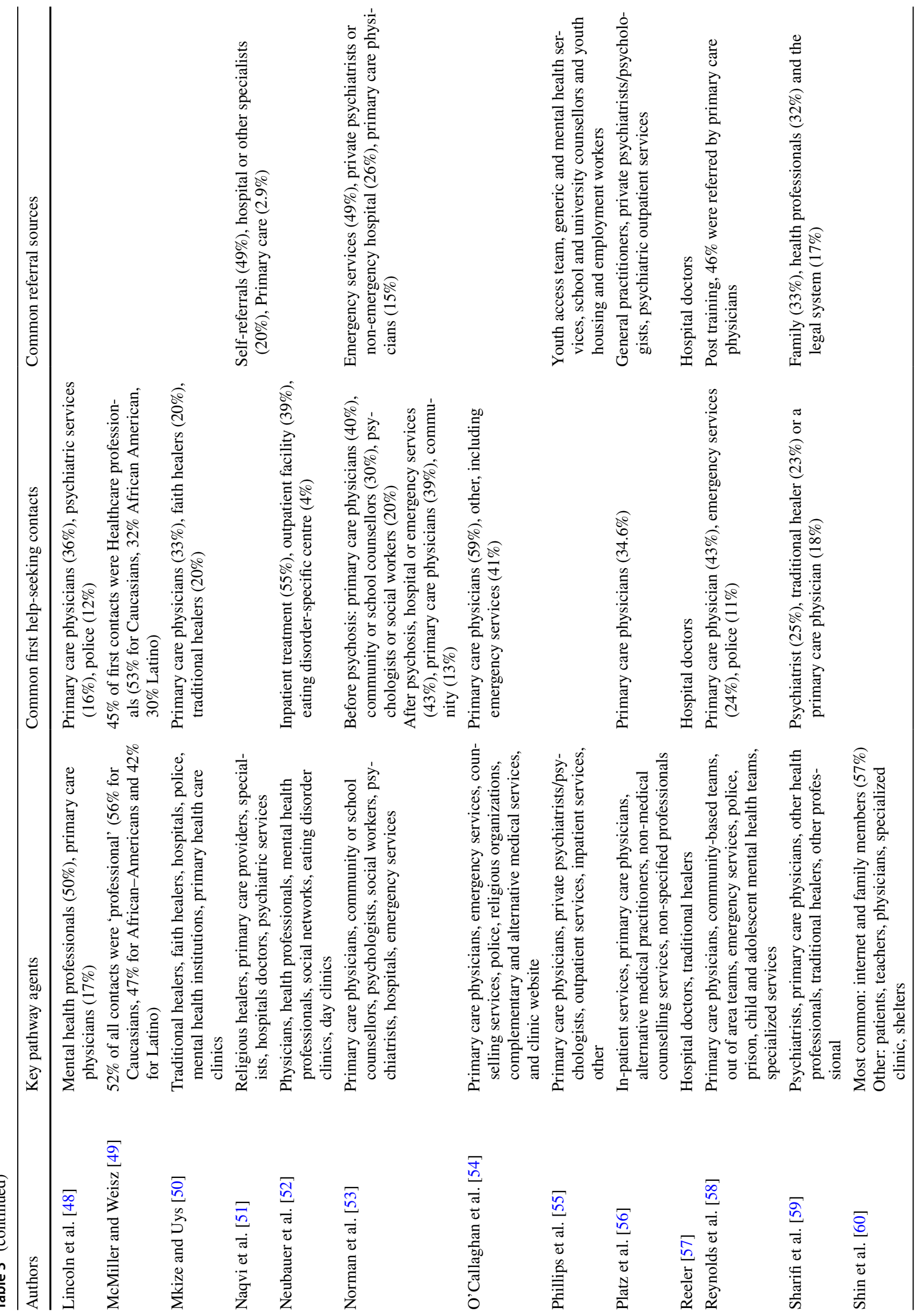




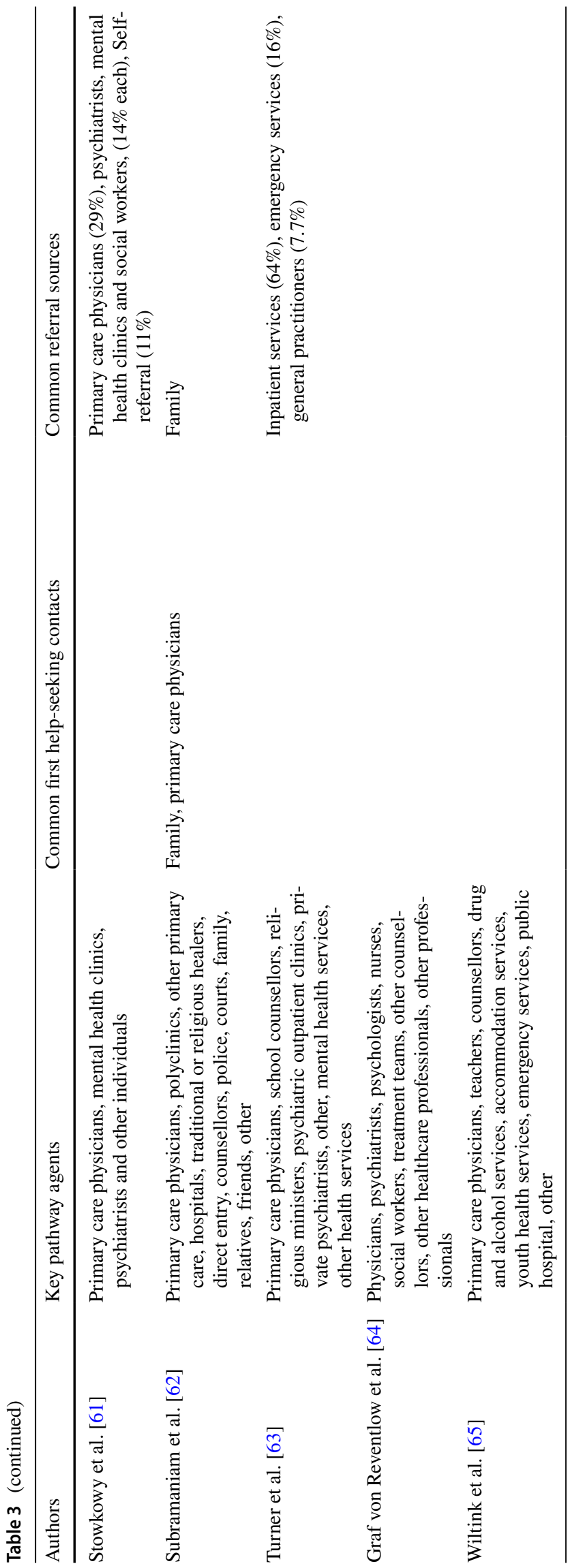

\section{Treatment delays}

Of the 39 studies that measured treatment delay, 23 were from first-episode psychosis settings, and 16 were from other mental health services (see Table 2).

\section{Duration of untreated psychosis (DUP)}

DUP is defined as the time between the onset of symptoms and the start of appropriate care (operationalized as the commencement of antipsychotic medication or admission to services). Across the 23 studies that reported DUP, mean DUP ranged from 1.5 to 102 weeks and median DUP ranged from 8 to 70 weeks. Of these 23 studies, 10 also assessed 'helpseeking delays' (time between the onset of initial symptoms and contact with the first pathway agent) and 'referral delays' (time between contact with the first pathway agent and the commencement of treatment at the study setting). Of these, three studies found that help-seeking delays exceeded referral delays [12, 34, 36]; six studies found referral delays to be longer, [35, 39, 40, 45, 48, 53]; and one study [54] found an even split between both delay components. Notably, FEP patients referred to a service for those at risk for psychosis reported longer referral, than help-seeking delays [56].

\section{Duration of untreated illness (DUI)}

Fifteen studies from a range of mental health settings described the length of treatment delays to their services. Although definitions of DUI varied, most studies conceptualized it as the time between the onset of symptoms and the commencement of treatment at their setting. DUI estimates ranged from 1 week to 45 years (Table 2). Despite our inclusion criteria focusing on young people between the ages of 11 and 30, the upper end of the range for DUI is 45 years. This is because we also included studies in which at least $50 \%$ of the included sample was in the age group of interest. Unfortunately, some of these studies did not break down their delay indices by age group (see Table 1 for participant characteristics for each included study.) At the very least, this wide range for DUI is indicative that there are often extremely lengthy delays before the receipt of appropriate treatment. Eight studies divided DUI into help-seeking and referral components. Of these, three studies reported lengthier help-seeking delays $[28,55,56]$ and five reported lengthier referral delays [41, 43, 46, 51, 64].

\section{Impact of pathways to care on treatment delays}

Seven studies found that encountering specific pathway agents affected treatment delay. One study [29] found that initial contacts with counsellors or courts led to longer DUPs. Another [42] found that DUP was shorter following 
referrals from emergency services. DUPs were shorter if the first contact was with general practitioners [59] and when comparing general practitioners to private psychiatrists and psychologists [56]. However, another study [12] reported longer referral delays for persons with FEP following contact with primary care, albeit such contact resulted in fewer negative pathways to care (e.g., emergency or inpatient services). In settings other than psychosis services, contacts with traditional or faith healers [46] or private general practitioners/ physicians [41] were notably associated with longer DUIs. Family involvement during help-seeking was associated with shorter help-seeking delays in one study [54].

\section{Factors influencing pathways to care}

Often, families/friends played a substantial role in the initiation of treatment. In two studies [26, 41], 70\% of participants had sought mental healthcare on the advice of family. One of these studies [41] contrasted this with the much lower rate of individuals deciding on their own to seek services $(16 \%)$. Families were found to be highly involved at various points along the pathway to care by recommending sources of help [28, 52], being the most common first source of help $[36,39,62]$, directly initiating contact $[31,41,54]$ or being the most common contact [37,60]. Studies' methodologies may have influenced their findings. For example, while 12 studies included families/relatives in their definitions of help-seeking contacts, 26 studies only considered professional contacts. Seven studies did not explicitly describe their inclusion criteria for pathway contacts.

\section{Negative pathways to care}

Negative pathways, generally defined as those involving contacts with the criminal justice system, emergency or inpatient units, are associated with poor patient experiences and disengagement [12]; and high costs, despite sometimes resulting in reduced treatment delays.

A number of studies explored the involvement of police and emergency services along pathways to care. In a study whose entire sample was African-American [34], over a quarter of participants had at least one contact with police, and police accounted for a fifth of all contacts. In another US study [33], the pathways of over half the Black participants featured some police involvement, a rate significantly higher than that observed in other ethnicities. In a Canadian study [24], emergency rooms were four and three times more likely to be the first contact for Asians and other ethnicities, respectively, than for White and Black participants. Overall, emergency services figured prominently as pathway agents across studies and contexts $(n=15)$.

\section{Costs}

Two studies [30, 44] examined the costs associated with various pathways to care. In a Canadian study [30], pathways to care involving inpatient units were 18.5 times costlier than pathways with no inpatient unit involvement. This was attributable to the greater involvement of police and emergency services with participants who ended up being inpatients. An Indian study demonstrated that the median monetary cost of an individual's pathway to care was more than half the average family's monthly income [44].

\section{Conceptual frameworks}

The only three studies that explicitly described being guided by a framework $[26,41,50]$ all used Goldberg and Huxley's conceptual framework [69]. This framework proposes that mental health problems manifest at five levels (from in the community to among those in specialized care), with individuals' advancement to subsequent levels being checked by selectively permeable filters that pertain to problem recognition (e.g., by general practitioners) and referral (e.g., to specialized care).

\section{Quality appraisal}

The methodological quality of the studies was mixed (see Table 4 for quality scores). Six studies met over $75 \%$ of the quality appraisal criteria; 34 studies met $50-75 \%$ of the criteria; and five studies met under $50 \%$ of the criteria. Key limitations were insufficient reporting on sample size determination; low participation rates or inadequate differentiation between participants and non-participants; and nonstandardized ascertainment of pathways to care.

\section{Discussion}

Pathways to mental healthcare for youths tend to be complex, with multiple help-seeking contacts, and, sometimes, lengthy delays before appropriate care begins. Across many contexts, general practitioners played a prominent role in the help-seeking process. The role of primary care is notable given the international consensus that integrating mental health services within primary care is essential to address gaps in mental healthcare provision [70].

In our reviewed studies, primary care physicians were more frequently among the first help-seeking contacts than a 'successful' referral source. To be the first line of mental healthcare, primary care providers must be adequately trained to effectively detect problems, render support, initiate treatment, coordinate with all healthcare tiers, and refer appropriately. 
Across settings, families played an influential role along pathways to care. This highlights the need for including families as pathway agents, something only few studies did. It also indicates that families need to be targeted in outreach efforts to reduce treatment delays for youths. Thus, giving due regard to families is important because familial involvement is known to mitigate the negative effects of and facilitate recovery from many mental illnesses [71].

Given the increasing rates of hospitalization and emergency visits among youths with mental health problems [72], and the high rates of emergency services involvement noted in our review, it is necessary to improve our understanding of the determinants of and trajectories to these endpoints that are associated with high personal and societal costs. Notably, the reviewed studies offer limited insights into what determines which youths follow these negative pathways, barring examinations of ethnicity as a determinant in the case of psychosis [23, 24, 33, 34].

Many of the factors leading to fragmented or difficult access to mental health services occur across age ranges. Studies assessing pathways to care in young children [73] and older adults [74] have also reported complex trajectories prior to obtaining services. Notably, however, many mental health systems have attributes that are known to disrupt care specifically for youth; chief among these being the transitions from child-adolescent to adult services [15]. These transitions, often rigid and poorly executed, can lead to disengagement from services and poor clinical outcomes. As such, it may be important for future research to prospectively assess pathways into and through services, and to pay specific attention to how transitions across mental health systems contribute to treatment delays and complicated pathways.

\section{Reconceptualising pathways to care beyond psychosis}

This review reveals that knowledge on pathways to care in youth mental health is largely driven by first-episode psychosis literature. This is likely due to the field's focus on reducing the DUP. Despite some disagreements on optimal treatment [75], there is enough consensus on care benchmarks for early psychosis researchers to clearly define 'appropriate care' and precisely delimit youths' pathways thereto. Also, most early intervention programs for psychosis target age groups that match our review's age-based selection criterion.

There is an evidence base for the adequacy of treatment for mental disorders other than psychosis [76]. Efforts to quantify treatment delays have also expanded to more disorders, with the adoption of DUI measures in bipolar [77], anxiety [78] and mood [79] disorders. Yet, specific inquiries into pathways to care across these disorders, at least with respect to youth-focused literature, remain limited, as does our understanding of the association between pathways to care and treatment delays.

The concept of appropriateness of pathway contacts warrants reflection. In early psychosis, contacts following the onset of frank psychotic symptoms that do not result in the commencement of psychosis-specific treatment can be viewed as missed opportunities for early intervention and prevention. More generally in youth, however, mental health symptom presentations are often transient and overlapping, and sometimes difficult to distinguish from developmentally normative behavioural or mood changes. It may therefore be difficult to establish an optimal 'pathway to care' in the broad field of youth mental health, and especially challenging to determine whether and when individuals reach an appropriate service. Two identical pathways may, in one case, reflect the appropriate use of a stepped-care model or, in another case, an inappropriately complex pathway. Moreover, even for similar problems, different individuals may have different optimal endpoints, based on available services, individual preferences, previous experiences, etc. Such complexities notwithstanding, studies on pathways to care can yield a greater understanding of how treatment gets delayed; and help identify the key agents involved in young peoples' help-seeking processes and targets for outreach.

It has been argued that 'one-stop' multidisciplinary integrated youth services [13] can improve pathways to mental healthcare for young people. A central tenet of these services is the concept that 'every door is the right door'. Such services aim to cater to youths with a range of needs (e.g., physical health, sexual health, mental health, housing, etc.) and types/severities of mental health problems. Examples of integrated youth services initiatives includes headspace in Australia [80], Jigsaw in Ireland [81], Youthspace in Birmingham, UK [82] and ACCESS Open Minds, Foundry and Youth Wellness Hubs Ontario in Canada [83-85].

Only one study in our review [43] focused on pathways to care at a cross-diagnostic service that addressed severe and complex mental health conditions. We strongly recommend that the transformation of youth mental healthcare, including the establishment of youth hubs within community settings, be accompanied by increasing study of pathways to this presumably desirable endpoint. Such research is pertinent given young people's preferences for community-based settings for mental healthcare [86].

\section{Contextual sensitivity}

Pathways to care are quite variable across geographies, reflecting differences in healthcare, social, and cultural contexts. Many studies reported the attributes of their healthcare systems that may have influenced pathways to care. Importantly, individuals contacted many providers before reaching even those services that had open referral systems. This is 
Table 4 Quality appraisal scores

\begin{tabular}{|c|c|c|c|c|c|c|c|c|c|}
\hline Study & $\begin{array}{l}\text { Research } \\
\text { question }\end{array}$ & $\begin{array}{l}\text { Representa- } \\
\text { tiveness of } \\
\text { participants }\end{array}$ & $\begin{array}{l}\text { Non-par- } \\
\text { ticipation } \\
\text { rate }\end{array}$ & $\begin{array}{l}\text { Adequacy of } \\
\text { sample size }\end{array}$ & $\begin{array}{l}\text { Adjustment } \\
\text { for confound- } \\
\text { ing factors }\end{array}$ & $\begin{array}{l}\text { Definition of } \\
\text { pathways to } \\
\text { care }\end{array}$ & $\begin{array}{l}\text { Ascertain- } \\
\text { ment of } \\
\text { pathways to } \\
\text { care }\end{array}$ & $\begin{array}{l}\text { Measurement } \\
\text { of pathways } \\
\text { to care }\end{array}$ & $\begin{array}{l}\text { Method of } \\
\text { ascertain- } \\
\text { ment }\end{array}$ \\
\hline $\begin{array}{l}\text { Addington } \\
\text { et al. [22] }\end{array}$ & + & • & + & - & - & + & + & + & + \\
\hline $\begin{array}{l}\text { Anderson } \\
\text { et al. [12] }\end{array}$ & + & + & + & - & + & + & + & + & + \\
\hline $\begin{array}{l}\text { Anderson } \\
\text { et al. [23] }\end{array}$ & + & • & + & - & + & + & + & + & + \\
\hline $\begin{array}{l}\text { Archie et al. } \\
{[24]}\end{array}$ & + & + & • & - & + & + & + & + & + \\
\hline Bakare [25] & + & - & - & - & - & + & + & - & + \\
\hline $\begin{array}{l}\text { Bekele et al. } \\
\text { [26] }\end{array}$ & + & - & - & - & + & + & - & + & + \\
\hline $\begin{array}{l}\text { Bhui et al. } \\
\text { [27] }\end{array}$ & + & - & - & - & + & - & - & + & + \\
\hline $\begin{array}{l}\text { Chadda et al. } \\
\text { [28] }\end{array}$ & + & - & - & - & + & - & - & + & + \\
\hline $\begin{array}{l}\text { Chesney et al. } \\
\text { [29] }\end{array}$ & + & - & - & - & - & + & + & - & + \\
\hline $\begin{array}{l}\text { Cheung et al. } \\
{[30]}\end{array}$ & + & + & - & - & - & + & + & + & + \\
\hline $\begin{array}{l}\text { Chiang et al. } \\
{[31]}\end{array}$ & + & - & - & - & - & - & + & - & + \\
\hline $\begin{array}{l}\text { Chien and } \\
\text { Compton } \\
{[32]}\end{array}$ & + & + & - & - & + & + & + & - & + \\
\hline $\begin{array}{c}\text { Commander } \\
\text { et al. [33] }\end{array}$ & + & + & + & - & - & + & - & - & + \\
\hline $\begin{array}{l}\text { Compton } \\
\text { et al. [34] }\end{array}$ & + & - & - & - & + & + & + & + & + \\
\hline $\begin{array}{l}\text { Cougnard } \\
\text { et al. [35] }\end{array}$ & + & - & + & - & + & + & + & - & + \\
\hline $\begin{array}{l}\text { Del Vecchio } \\
\text { et al. [36] }\end{array}$ & + & - & - & - & + & + & + & + & + \\
\hline $\begin{array}{l}\text { Ehmann et al. } \\
\text { [37] }\end{array}$ & + & • & - & - & - & + & + & + & + \\
\hline $\begin{array}{l}\text { Etheridge } \\
\text { et al. [38] }\end{array}$ & + & - & - & - & - & - & - & - & + \\
\hline $\begin{array}{l}\text { Fridgen al } \\
\text { [39] }\end{array}$ & + & + & - & - & • & + & - & - & + \\
\hline $\begin{array}{l}\text { Fuchs and } \\
\text { Steinert [40] }\end{array}$ & + & - & + & - & - & - & - & - & + \\
\hline $\begin{array}{l}\text { Giasuddin } \\
\text { et al. [41] }\end{array}$ & + & + & + & + & + & + & - & + & + \\
\hline $\begin{array}{l}\text { Hastrup et al. } \\
\text { [42] }\end{array}$ & + & + & + & - & + & - & - & - & + \\
\hline $\begin{array}{l}\text { Hodgekins } \\
\text { et al. [43] }\end{array}$ & + & - & - & - & - & + & + & + & + \\
\hline Jain et al. [44] & + & - & + & - & - & + & + & + & + \\
\hline $\begin{array}{l}\text { Judge et al. } \\
\text { [45] }\end{array}$ & + & - & - & - & - & + & + & - & + \\
\hline $\begin{array}{l}\text { Kurihara et al. } \\
\text { [46] }\end{array}$ & + & - & + & - & - & + & + & + & + \\
\hline
\end{tabular}


Table 4 (continued)

\begin{tabular}{|c|c|c|c|c|c|c|c|c|c|}
\hline Study & $\begin{array}{l}\text { Research } \\
\text { question }\end{array}$ & $\begin{array}{l}\text { Representa- } \\
\text { tiveness of } \\
\text { participants }\end{array}$ & $\begin{array}{l}\text { Non-par- } \\
\text { ticipation } \\
\text { rate }\end{array}$ & $\begin{array}{l}\text { Adequacy of } \\
\text { sample size }\end{array}$ & $\begin{array}{l}\text { Adjustment } \\
\text { for confound- } \\
\text { ing factors }\end{array}$ & $\begin{array}{l}\text { Definition of } \\
\text { pathways to } \\
\text { care }\end{array}$ & $\begin{array}{l}\text { Ascertain- } \\
\text { ment of } \\
\text { pathways to } \\
\text { care }\end{array}$ & $\begin{array}{l}\text { Measurement } \\
\text { of pathways } \\
\text { to care }\end{array}$ & $\begin{array}{l}\text { Method of } \\
\text { ascertain- } \\
\text { ment }\end{array}$ \\
\hline $\begin{array}{l}\text { Lahariya et al. } \\
\text { [47] }\end{array}$ & + & • & + & - & • & - & + & + & + \\
\hline $\begin{array}{l}\text { Lincoln et al. } \\
\text { [48] }\end{array}$ & + & • & + & - & + & - & - & + & + \\
\hline $\begin{array}{l}\text { McMiller and } \\
\text { Weisz [49] }\end{array}$ & + & • & • & - & - & + & - & - & + \\
\hline $\begin{array}{r}\text { Mkize and } \\
\text { Uys [50] }\end{array}$ & + & - & - & + & + & + & - & + & + \\
\hline $\begin{array}{l}\text { Naqvi et al. } \\
\text { [51] }\end{array}$ & + & + & - & - & - & - & - & - & + \\
\hline $\begin{array}{l}\text { Neubauer } \\
\text { et al. [52] }\end{array}$ & + & - & + & - & + & + & + & - & + \\
\hline $\begin{array}{l}\text { Norman et al. } \\
\text { [53] }\end{array}$ & + & • & - & - & • & + & + & + & + \\
\hline $\begin{array}{c}\text { O'Callaghan } \\
\text { et al. [54] }\end{array}$ & + & - & + & - & + & + & • & - & + \\
\hline $\begin{array}{l}\text { Phillips et al. } \\
\text { [55] }\end{array}$ & + & • & • & - & - & - & + & - & + \\
\hline $\begin{array}{l}\text { Platz et al. } \\
\text { [56] }\end{array}$ & + & + & - & - & - & - & + & - & + \\
\hline Reeler [57] & + & • & - & - & - & + & - & + & + \\
\hline $\begin{array}{l}\text { Reynolds } \\
\text { et al. [58] }\end{array}$ & + & • & • & - & + & + & - & - & + \\
\hline $\begin{array}{l}\text { Sharifi et al. } \\
\text { [59] }\end{array}$ & + & + & + & - & • & + & + & - & + \\
\hline $\begin{array}{l}\text { Shin et al. } \\
\text { [60] }\end{array}$ & + & • & - & - & • & + & • & - & + \\
\hline $\begin{array}{l}\text { Stowkowy } \\
\text { et al. [61] }\end{array}$ & + & - & - & - & + & + & + & + & + \\
\hline $\begin{array}{l}\text { Subramaniam } \\
\text { et al. [62] }\end{array}$ & + & - & - & - & + & + & • & - & + \\
\hline $\begin{array}{l}\text { Turner et al. } \\
\text { [63] }\end{array}$ & + & • & + & - & $\bullet$ & + & $\bullet$ & - & + \\
\hline $\begin{array}{l}\text { Graf von } \\
\text { Reventlow } \\
\text { et al. [64] }\end{array}$ & + & + & + & - & + & - & + & + & + \\
\hline $\begin{array}{l}\text { Wiltink et al. } \\
\text { [65] }\end{array}$ & + & • & • & - & - & + & • & - & + \\
\hline
\end{tabular}

- , Criterion not met; $\bullet$, Criterion partially met; + , Criterion satisfied

perhaps unsurprising, given that, at least in psychosis, service configuration alone does not appear to impact treatment delays [87]. This finding underscores the importance of early identification and outreach in reducing treatment delays [66] as rapid access to care depends not only on systemic factors, but also on such influencers of help-seeking such as stigma, mental health literacy, and awareness of available services $[88,89]$.

Notably too, some studies reported longer referral delays than help-seeking delays, suggesting that the delay in treatment was attributable more to the care system itself. One can therefore conclude that the effort to reduce treatment delays and simplify pathways has to be directed at both the help-seeking and the referral components of treatment delay.

The importance of primary care physicians prevailed in settings promoting 'stepped care' or general practitionergatekeeper models (e.g., Canada, Australia and Western Europe). Some contexts that allowed direct access to specialized care were likely to report self- or family-initiated 
referrals. In general, the role of general practitioners seems to be influenced by features of the healthcare system such as the availability and affordability of private or public mental health professionals.

Our review included studies from both low- and middleincome countries (LMICs) and high-income countries. With more than $80 \%$ of the world's population, LMICs deploy less than $20 \%$ of the world's mental health resources [90]. Often in LMICs, specialized care is inaccessible to many. These differences were reflected in our review. Certain LMICbased studies described a difficulty in accessing formal mental healthcare, and cultural factors that influenced helpseeking (e.g., faith healers). More pathways to care research is needed in LMICs that have begun emphasising the integration of youth mental healthcare into existing community structures such as school, primary care, and community campaigns [91]. Such research can yield valuable insights on whether pathways to mental health care are simplified when addressed through larger public health promotion and development initiatives.

Notably, only four studies were from the United States, a country that otherwise generates volumes of mental health research. This suggests that interest in pathways to care may itself be a feature of public healthcare systems.

Studies on pathways to care need to better report on the organization of local mental health services/systems, and beliefs about illnesses and services. This would help contextualize the appropriateness of potential routes to care across contexts.

\section{Measuring pathways to care}

Many challenges remain in the assessment of pathways to care. The lack of standardization in the measurement of pathways to care is a major limitation that, in psychosis research, has been identified for over a decade [16].

Wide variance in the definitions of start- and endpoints of pathways; and what and who constitutes a help-seeking contact limits our ability to compare results across studies. In many cases, the instruments chosen to assess pathways to care had a major influence on findings. Studies varied in their inclusion of formal, informal and 'novel' (e.g., webbased) contacts. The only study that specifically probed it, found that the internet figured prominently in the help-seeking process.

Only three studies mentioned being guided by a theoretical framework, despite the frameworks for help-seeking behaviour and service use being available since the early 1990s [92, 93] and having been modified for mental healthcare pathways research.

Studies on pathways to care are often premised on assumptions about the desirability of fewer contacts and, less frequently, the undesirability of certain types of contacts.
Most studies are descriptive and provide estimates of individual and aggregate numbers and types of contacts made before a defined endpoint. However, evidence is lacking for whether more contacts along the pathway necessarily translate into longer treatment delays. Factors other than simply the number and type of contacts (e.g., waitlists, multiple encounters with the same contact, multiple contacts ending in evaluation but no treatment, etc.) may have a greater impact on treatment delays. Furthermore, reports of the numbers and types of help-seeking contacts do not reveal whether different services were accessed concurrently; whether appropriate treatments or referrals were offered and declined; or whether contacts met the individual's needs. Also, notably absent is any measurement of how youths themselves perceived various help-seeking contacts.

To advance research on pathways to youth mental healthcare and, thereby, youth mental health outcomes, we outline some key recommendations informed by our review. An important first step is standardization in the reporting of pathways to care. Specific recommendations in this regard are:

a. Making it a standard to use and report theoretical frameworks in pathways to care research would facilitate better comparability across studies, more meaningful syntheses of extant knowledge, and easier identification of gaps.

b. Studies on pathways to care should define pathways clearly, specifying start and endpoints.

c. Studies should describe their intended methods of assessing pathways to care, justifying the choice of methodology in relation to study aims and the chosen theoretical framework. Ideally, an instrument with established psychometric properties should be used. Where a novel instrument is used, its psychometric properties must be established and/or described.

d. The instruments should use a clearly specified timeframe, and techniques such as anchor dates should be employed to reduce the effects of telescoping bias, whereby events are recalled as occurring earlier or more recently than they actually did [94]. This will allow for the accurate estimation of treatment delay indices.

e. Studies should report on whether specific types of contacts were defined a priori or post hoc after collecting personal narratives, and whether specific types of contacts such as informal contacts (e.g., friends) and online resources were probed for in the interview.

f. Studies should describe key features of the healthcare context (e.g., universal healthcare, access based on insurance, etc.) and referral system (e.g., walk-in access; need for a referral from a general practitioner, etc.) of their study setting. 
The emergence of integrated youth services that, across geographic contexts, strive to adhere to common principles [95] provides both a framework and an impetus for standardising the measurement of pathways to care. In addition to addressing the considerations for reporting of pathways to care outlined above, a standardized measure for pathways to care to be used across youth services should be relevant to and feasible for implementation in a range of contexts (urban, rural, Indigenous, high- or low-income, etc.). An ideal measure would capture pathways into the service (e.g., walk-in, referral, etc.); what was offered at the service (e.g., evaluation, short- or long-term treatment, crisis intervention, etc.); and pathways out of the service.

Integrated youth services aim to offer well-publicised, rapidly accessible entry into a range of services and supports (not only those pertaining to mental health). The implicit assumption that such broad-spectrum services translate into more direct pathways and shorter delays to appropriate mental healthcare needs empirical testing. Some integrated youth services only offer interventions to those with mild to moderate mental and substance use concerns, referring more complex cases to external services. Future research therefore needs to examine whether such integrated youth services also succeed in simplifying pathways to care for youth with complex presentations.

A foundational principle of current endeavours to transform youth mental healthcare has been a commitment to making services youth-oriented, and engaging youths in service design and evaluation. Consistent with this, the creation or deployment of any standardized measure of pathways to care should be conducted in partnership with youths and their families, and should pay due regard to youths' perceptions of their pathways into care. Future studies would also do well to enquire about e-pathways to care, as youths are known to turn to the internet and social media in seeking mental health help [96].

\section{Limitations}

Our potential for comparisons across contexts and populations was limited by the lack of a standard methodology for ascertaining and reporting pathways to care. Our review's scope was shaped by its inclusion of only quantitative studies that tend to focus on numbers and types of help-seeking contacts. Other significant aspects of the help-seeking process, such as beliefs about illnesses, and perceived barriers and facilitators to help-seeking, are largely found in qualitative analyses of pathways to care. Quantitative and qualitative approaches can have complementary potentialities in pathways to care research [97]. Our age-based criterion was deliberately broad to accommodate studies that may have included, but not solely focused on, youths. However, this impedes our confidence in the applicability of our findings to exclusively youthfocused settings.

\section{Conclusion}

Across contexts, young people's pathways to mental healthcare are often complex and involve various formal and informal agents. Further research is necessary to better understand, and ultimately, to simplify and streamline pathways to appropriate services. This is an essential step towards ensuring easier, timelier access to care and, thereby, shaping youth mental health outcomes. More research is needed to address critical gaps in our knowledge of young people's pathways to care for problems other than psychosis; the determinants of pathways; and the help-seeking behaviours of and service responses to underserved groups such as Indigenous youths, youth in protection/welfare systems, and homeless youths.

Acknowledgements The authors wish to thank Gerald Jordan, Megan Pope, and Kevin MacDonald for inputs on drafts of this manuscript. The study was funded by a Canadian Institutes of Health Research (CIHR) Foundation Grant (Iyer). K. MacDonald is supported by a Fonds de Recherche du Québec-Santé (FRQS) Doctoral Scholarship in partnership with Quebec's Strategy for Patient-Oriented Research Support Unit, as well as an ACCESS Open Minds Doctoral Studentship. K. Anderson is supported by a New Investigator Fellowship from the Ontario Mental Health Foundation and an Early Researcher Award from the Ontario Ministry of Research, Innovation, and Science. S. Iyer is funded through the CIHR New Investigator Salary Award Program and has previously received salary support from FRQS.

\section{Compliance with ethical standards}

Conflict of interest The authors declare that they have no conflict of interest.

Open Access This article is distributed under the terms of the Creative Commons Attribution 4.0 International License (http://creativeco mmons.org/licenses/by/4.0/), which permits unrestricted use, distribution, and reproduction in any medium, provided you give appropriate credit to the original author(s) and the source, provide a link to the Creative Commons license, and indicate if changes were made.

\section{References}

1. Kessler RC, Berglund P, Demler O, Jin R, Merikangas KR, Walters EE (2005) Lifetime prevalence and age-of-onset distributions of DSM-IV disorders in the national comorbidity survey replication. Arch Gen Psychiatry 62:593-602. https://doi.org/10.1001/ archpsyc.62.6.593

2. Erskine H, Moffitt TE, Copeland W, Costello E, Ferrari A, Patton G, Degenhardt L, Vos T, Whiteford H, Scott J (2015) A heavy burden on young minds: the global burden of mental and substance 
use disorders in children and youth. Psychol Med 45(7):15511563. https://doi.org/10.1017/S0033291714002888

3. Farmer EMZ, Burns BJ, Phillips SD, Angold A, Costello EJ (2003) Pathways into and through mental health services for children and adolescents. Psychiatr Serv 54:60-66. https://doi. org/10.1176/appi.ps.54.1.60

4. Arnett JJ (2000) Emerging adulthood. A theory of development from the late teens through the twenties. Am Psychol 55(5):469480. https://doi.org/10.1037/0003-066X.55.5.469

5. McGorry P (2011) Transition to adulthood: the critical period for pre-emptive, disease-modifying care for schizophrenia and related disorders. Schizophr Bull 37(3):524-530. https://doi.org/10.1093/ schbul/sbr027

6. Wang PS, Berglund P, Olfson M, Pincus HA, Wells KB, Kessler RC (2005) Failure and delay in initial treatment contact after first onset of mental disorders in the National Comorbidity Survey Replication. Arch Gen Psychiatry 62(6):603-613. https://doi. org/10.1001/archpsyc.62.6.603

7. Dell'Osso B, Altamura AC (2010) Duration of untreated psychosis and duration of untreated illness: New Vistas. CNS Spectr 15(4):238-246. https://doi.org/10.1017/S1092852900000079

8. Rogler LH, Cortes DE (1993) Help-seeking pathways: a unifying concept in mental health care. Am J Psychiatry 150(4):554-561. https://doi.org/10.1176/ajp.150.4.554

9. Gater R, De Almeida E, Sousa B, Barrientos G, Caraveo J, Chandrashekar CR, Dhadphale M, Goldberg D, Al Kathiri AH, Mubbashar M, Silhan K, Thong D, Torres-Gonzales F, Sartorius N (1991) The pathways to psychiatric care: a cross-cultural study. Psychol Med 21:761-774. https://doi.org/10.1017/S003329170 002239X

10. Perkins D, Gu H, Boteva K, Lieberman J (2005) Relationship between duration of untreated psychosis and outcome in firstepisode schizophrenia: a critical review and meta-analysis. Am J Psychiatry 162:1785-1804. https://doi.org/10.1176/appi. ajp.162.10.1785

11. Anderson K, Fuhrer R, Malla A (2010) The pathways to mental health care of first-episode psychosis patients: a systematic review. Psychol Med 40(10):1585-1597. https://doi.org/10.1017/S0033 291710000371

12. Anderson KK, Fuhrer R, Schmitz N, Malla AK (2013) Determinants of negative pathways to care and their impact on service disengagement in first-episode psychosis. Soc Psychiatry Psychiatr Epidemiol 48(1):125-136. https://doi.org/10.1007/s0012 7-012-0571-0

13. Malla A, Iyer S, McGorry P, Cannon M, Coughlan H, Singh S, Jones P, Joober R (2015) From early intervention in psychosis to youth mental health reform: a review of the evolution and transformation of mental health services for young people. Soc Psychiatry Psychiatr Epidemiol 51(3):1-8. https://doi.org/10.1007/ s00127-015-1165-4

14. Alonso J, Angermeyer MC, Bernert S, Bruffaerts R, Brugha TS, Bryson H, de Girolamo G, Graaf R, Demyttenaere K, Gasquet I, Haro JM, Katz SJ, Kessler RC, Kovess V, Lepine JP, Ormel J, Polidori G, Russo LJ, Vilagut G, Almansa J, ArbabzadehBouchez S, Autonell J, Bernal M, Buist-Bouwman MA, Codony M, Domingo-Salvany A, Ferrer M, Joo SS, Martinez-Alonso M, Matschinger H, Mazzi F, Morgan Z, Morosini P, Palacin C, Romera B, Taub N, Vollebergh WA, Project ESotEoMDE (2004) Use of mental health services in Europe: results from the European Study of the Epidemiology of Mental Disorders (ESEMeD) project. Acta Psychiatr Scand Suppl 109(420):47-54. https://doi. org/10.1111/j.1600-0047.2004.00330.x

15. Singh S (2009) Transition of care from child to adult mental health services: the great divide. Curr Opin Psychiatry 22:386-390. https ://doi.org/10.1097/YCO.0b013e32832c9221
16. Singh SP, Grange T (2006) Measuring pathways to care in firstepisode psychosis: a systematic review. Schizophr Res 81(1):7582. https://doi.org/10.1016/j.schres.2005.09.018

17. Volpe U, Mihai A, Jordanova V, Sartorius N (2015) The pathways to mental healthcare worldwide: a systematic review. Curr Opin Psychiatry 28(4):299-306. https://doi.org/10.1097/YCO.00000 00000000164

18. Rosen A, Byrne P, Goldstone S, McGorry P (2015) Early intervention for better mental health services. In: Tasman A, Kay J, Lieberman JA (eds) Psychiatry, 4th edn. Wiley Blackwell, Hoboken, pp 1990-2010

19. Moher D, Tetzlaff J, Altman DGLA, The PRISMA Group (2009) Preferred reporting items for systematic reviews and meta-analyses: the PRISMA statement. Ann Intern Med 151:264-269. https ://doi.org/10.7326/0003-4819-151-4-200908180-00135

20. Wells GA, Shea B, O'Connell D, Peterson J, Welch V, Losos M, Tugwell P (2013) The Newcastle-Ottawa Scale (NOS) for assessing the quality of nonrandomized studies in meta-analyses. The Ottawa Hospital Research Institute, pp 1-4. http://www.ohri.ca/ programs/clinical_epidemiology/oxford.asp. Accessed 26 Nov 2017

21. Anderson KK, Flora N, Archie S, Morgan C, McKenzie K (2014) A meta-analysis of ethnic differences in pathways to care at the first episode of psychosis. Acta Psychiatr Scand 130(4):257-268. https://doi.org/10.1111/acps.12254

22. Addington J, Van Mastrigt S, Hutchinson J, Addington D (2002) Pathways to care: help seeking behaviour in first episode psychosis. Acta Psychiatr Scand 106(5):358-364

23. Anderson KK, Flora N, Ferrari M, Tuck A, Archie S, Kidd S, Tang T, Kirmayer LJ, McKenzie K (2015) Pathways to first-episode care for psychosis in African-, Caribbean-, and European-origin groups in Ontario. Can J Psychiatry 60:223-231. https://doi. org/10.1177/070674371506000504

24. Archie S, Akhtar-Danesh N, Norman R, Malla A, Roy P, Zipursky RB (2008) Ethnic diversity and pathways to care for a first episode of psychosis in Ontario. Schizophr Bull 36(4):688-701. https:// doi.org/10.1093/schbul/sbn137

25. Bakare MO (2013) Pathway to care: first points of contact and sources of referral among children and adolescent patients seen at neuropsychiatric hospital in South-Eastern Nigeria. Niger J Med 22(1):52-56

26. Bekele YY, Flisher AJ, Alem A, Baheretebeb Y (2009) Pathways to psychiatric care in Ethiopia. Psychol Med 39:475-483. https:// doi.org/10.1017/S0033291708003929

27. Bhui K, Ullrich S, Coid JW (2014) Which pathways to psychiatric care lead to earlier treatment and a shorter duration of first-episode psychosis? BMC Psychiatry 14(1):72

28. Chadda RK, Agarwal V, Singh MC, Raheja D (2001) Help seeking behaviour of psychiatric patients before seeking care at a mental hospital. Int J Soc Psychiatry 47:71-78. https://doi. org/10.1177/002076400104700406

29. Chesney E, Abdin E, Poon LY, Subramaniam M, Verma S (2016) Pathways to care for patients with first-episode psychosis in Singapore. J Nerv Ment Dis 204(4):291-297. https://doi.org/10.1097/ NMD.0000000000000464

30. Cheung D, Roper L, Purdon SE (2014) Pathways to (specialized) care: patient costs and contacts en route to a first-episode psychosis clinic. Early Interv Psychiatry 8:375-381. https://doi. org/10.1111/eip.12093

31. Chiang J, Chow AS, Chan RC, Law C, Chen EY (2005) Pathway to care for patients with first-episode psychosis in Hong Kong. Hong Kong J Psychiatry 15:18-22

32. Chien VH, Compton MT (2008) The impact of mode of onset of psychosis on pathways to care in a hospitalized, predominantly African-American, first-episode sample. Early Interv Psychiatry 2(2):73-79 
33. Commander MJ, Cochrane R, Sashidharan SP, Akilu F, Wildsmith E (1999) Mental health care for Asian, black and white patients with non-affective psychoses: pathways to the psychiatric hospital, in-patient and after-care. Soc Psychiatry Psychiatr Epidemiol 34:484-491. https://doi.org/10.1007/s001270050224

34. Compton MT, Esterberg ML, Druss BG, Walker EF, Kaslow NJ (2006) A descriptive study of pathways to care among hospitalized urban African American first-episode schizophrenia-spectrum patients. Soc Psychiatry Psychiatr Epidemiol 41(7):566-573. https://doi.org/10.1007/s00127-006-0065-Z

35. Cougnard A, Kalmi E, Desage A, Misdrahi D, Abalan F, BrunRousseau H, Salmi LR, Verdoux H (2004) Pathways to care of first-admitted subjects with psychosis in South-Western France. Psychol Med 34(2):267-276. https://doi.org/10.1017/s003329170 300120x

36. Del Vecchio V, Luciano M, Sampogna G, De Rosa C, Giacco D, Tarricone I, Catapano F, Fiorillo A (2015) The role of relatives in pathways to care of patients with a first episode of psychosis. Int J Soc Psychiatry 61:631-637. https://doi.org/10.1177/00207 64014568129

37. Ehmann TS, Tee KA, Macewan GW, Dalzell KL, Hanson LA, Smith GN, Kopala LC (2014) Treatment delay and pathways to care in early psychosis. Early Interv Psychiatry 8:240-246. https ://doi.org/10.1111/eip.12051

38. Etheridge K, Yarrow L, Peet M (2004) Pathways to care in first episode psychosis. J Psychiatr Mental Health Nurs 11(2): $125-128$

39. Fridgen GJ, Aston J, Gschwandtner U, Pflueger M, Zimmermann R, Studerus E, Stieglitz RD, Riecher-Rossler A (2013) Help-seeking and pathways to care in the early stages of psychosis. Soc Psychiatry Psychiatr Epidemiol 48(7):1033-1043. https://doi.org/10.1007/s00127-012-0628-0

40. Fuchs J, Steinert T (2004) Patients with a first episode of schizophrenia spectrum psychosis and their pathways to psychiatric hospital care in South Germany. Soc Psychiatry Psychiatr Epidemiol 39(5):375-380. https://doi.org/10.1007/s0012 7-004-0767-z

41. Giasuddin NA, Chowdhury NF, Hashimoto N, Fujisawa D, Waheed S (2012) Pathways to psychiatric care in Bangladesh. Social Psychiatry Psychiatr Epidemiol 47:129-136. https://doi. org/10.1007/s00127-010-0315-y

42. Hastrup LH, Haahr UH, Jansen JE, Simonsen E (2018) Determinants of duration of untreated psychosis among first-episode psychosis patients in Denmark: a nationwide register-based study. Schizophr Res 192:154-158. https://doi.org/10.1016/j. schres.2017.05.026

43. Hodgekins J, Clarke T, Cole H, Markides C, Ugochukwu U, Cairns P, Lower R, Fowler D, Wilson J (2016) Pathways to care of young people accessing a pilot specialist youth mental health service in Norfolk, United Kingdom. Early Interv Psychiatry 11(5):436-443. https://doi.org/10.1111/eip.12338

44. Jain N, Gautam S, Jain S, Gupta ID, Batra L, Sharma R, Singh $\mathrm{H}$ (2012) Pathway to psychiatric care in a tertiary mental health facility in Jaipur, India. Asian J Psychiatry 5:303-308. https://doi. org/10.1016/j.ajp.2012.04.003

45. Judge AM, Perkins DO, Nieri J, Penn DL (2005) Pathways to care in first episode psychosis: a pilot study on help-seeking precipitants and barriers to care. J Ment Health 14:465-469. https://doi. org/10.1080/09638230500271089

46. Kurihara T, Kato M, Reverger R, Tirta IGR (2006) Pathway to psychiatric care in Bali. Psychiatry Clin Neurosci 60:204-210. https://doi.org/10.1111/j.1440-1819.2006.01487

47. Lahariya C, Singhal S, Gupta S, Mishra A (2010) Pathway of care among psychiatric patients attending a mental health institution in central India. Indian J Psychiatry 52(4):333
48. Lincoln C, Harrigan S, McGorry PD (1998) Understanding the topography of the early psychosis pathways: an opportunity to reduce delays in treatment. Br J Psychiatry 172(33):21-25. https ://doi.org/10.1192/S0007125000297614

49. McMiller WP, Weisz JR (1996) Help-seeking preceding mental health clinic intake among African-American, Latino, and Caucasian youths. J Am Acad Child Adolesc Psychiatry 35(8):1086-1094

50. Mkize L, Uys L (2004) Pathways to mental health care in KwaZulu-Natal. Curationis 27(3):62-71. https://doi.org/10.4102/curat ionis.v27i3.1001

51. Naqvi HA, Khan MM (2006) Pathway to psychiatric care in Karachi. J Coll Physicians Surg Pak 16(6):438-439. https://doi. org/10.1371/journal.pone.0007409

52. Neubauer K, Weigel A, Daubmann A, Wendt H, Rossi M, Löwe B, Gumz A (2014) Paths to first treatment and duration of untreated illness in anorexia nervosa: are there differences according to age of onset? Eur Eat Disord Rev 22:292-298. https://doi.org/10.1002/ erv. 2300

53. Norman R, Malla A, Verdi M, Hassall L, Fazekas C (2004) Understanding delay in treatment for first-episode psychosis. Psychol Med 34(2):255-266. https://doi.org/10.1017/S00332917030011 19

54. O'Callaghan E, Turner N, Renwick L, Jackson D, Sutton M, Foley SD, McWilliams S, Behan C, Fetherstone A, Kinsella A (2010) First episode psychosis and the trail to secondary care: help-seeking and health-system delays. Soc Psychiatry Psychiatr Epidemiol 45(3):381-391. https://doi.org/10.1007/s00127-009-0081-x

55. Phillips L, Yung AR, Hearn N, McFarlane C, Hallgren M, McGorry PD (1999) Preventive mental health care: accessing the target population. Aust N Z J Psychiatry 33(6):912-917. https:// doi.org/10.1046/j.1440-1614.1999.00613.x

56. Platz C, Umbricht DS, Cattapan-Ludewig K, Dvorsky D, Arbach D, Brenner HD, Simon AE (2006) Help-seeking pathways in early psychosis. Soc Psychiatry Psychiatr Epidemiol 41(12):967-974. https://doi.org/10.1007/s00127-006-0117-4

57. Reeler AP (1992) Pathways to psychiatric care in Harare, Zimbabwe. Cent Afr J Med 38(1):1-7

58. Reynolds N, Wuyts P, Badger S, Fusar-Poli P, McGuire P, Valmaggia L (2015) The impact of delivering GP training on the clinical high risk and first-episode psychosis on referrals and pathways to care. Early Interv Psychiatry 9(6):459-466

59. Sharifi V, Kermani-Ranjbar T, Amini H, Alaghband-rad J, Salesian N, Seddigh A (2009) Duration of untreated psychosis and pathways to care in patients with first-episode psychosis in Iran. Early Interv Psychiatry 3(2):131-136. https://doi.org/10.111 1/j.1751-7893.2009.00119.x

60. Shin YM, Jung HY, Kim SW, Lee SH, Shin SE, Park JI, An SK, Kim YH, Chung YC (2010) A descriptive study of pathways to care of high risk for psychosis adolescents in Korea. Early Interv Psychiatry 4(2):119-123. https://doi.org/10.111 1/j.1751-7893.2010.00180.x

61. Stowkowy J, Colijn MA, Addington J (2013) Pathways to care for those at clinical high risk of developing psychosis. Early Interv Psychiatry 7(1):80-83

62. Subramaniam M, Zheng H, Soh P, Poon LY, Vaingankar JA, Chong SA, Verma S (2016) Typology of people with first-episode psychosis. Early Interv Psychiatry 10:346-354. https://doi. org/10.1111/eip.12178

63. Turner M, Turner M, Smith-Hamel C, Mulder R (2006) Pathways to care in a New Zealand firstepisode of psychosis cohort. Aust N Z J Psychiatry 40(5):421-428

64. Graf von Reventlow H, Krüger-Özgürdal S, Ruhrmann S, Schultze-Lutter F, Heinz A, Patterson P, Heinimaa M, Dingemans P, French P, Birchwood M, Salokangas RK, Linszen D, Morrison A, Klosterkötter J, Juckel G (2014) Pathways to care in 
subjects at high risk for psychotic disorders-a European perspective. Schizophr Res 152:400-407. https://doi.org/10.1016/j.schre s.2013.11.031

65. Wiltink S, Velhorst E, Nelson B, McGorry PM, Yung AR (2015) Declining transitions rates to psychosis: the contribution of potential changes in referral pathways to an ultra-high-risk service. Early Interv Psychiatry 9(3):200-206. https://doi.org/10.1111/ eip. 12105

66. Norman R, Malla A, Verdi M, Hassall L, Fazekas C (2004) Understanding delay in treatment for first-episode psychosis. Psychol Med 34(2):255-266. https://doi.org/10.1017/S00332917030011 19

67. Perkins D, Nieri J, Bell K, Lieberman J (1999) Factors that contribute to delay in the initial treatment of psychosis. Schizophr Res 36:52

68. Riecher-Rössler A, Aston J, Ventura J, Merlo M, Borgwardt S, Gschwandtner U, Stieglitz RD (2008) The Basel Screening Instrument for Psychosis (BSIP): development, structure, reliability and validity. Fortschr Neurol Psychiatr 76:207-216. https://doi. org/10.1055/s-2008-1038155

69. Huxley P (1996) Mental illness in the community: the GoldbergHuxley model of the pathway to psychiatric care. Nord J Psychiatry 50:47-53. https://doi.org/10.3109/08039489609099730

70. Kohn R, Saxena S, Levav I, Saraceno B (2004) The treatment gap in mental health care. Bull World Health Organ 82:858-866. https ://doi.org/10.1590/S0042-96862004001100011

71. Davidson L, White W (2007) The concept of recovery as an organizing principle for integrating mental health and addiction services. J Behav Health Serv Res. https://doi.org/10.1007/s1141 4-007-9053-7

72. Canadian Institute for Health Information (2015) Care for Children and Youth with Mental Disorders. CIHI. https://secure.cihi. ca/free_products/CIHI\%20CYMH\%20Final\%20for\%20pubs_EN_ web.pdf. Accessed 15 Jan 2018

73. Sayal K, Taylor E, Beecham J, Byrne P (2002) Pathways to care in children at risk of attention-deficit hyperactivity disorder. $\mathrm{Br} \mathrm{J}$ Psychiatry 181(1):43-48. https://doi.org/10.1192/bjp.181.1.43

74. Mukadam N, Cooper C, Livingston G (2011) A systematic review of ethnicity and pathways to care in dementia. Int J Geriatr Psychiatry 26(1):12-20. https://doi.org/10.1002/gps.2484

75. Malla AM, Norman RMG (2001) Treating psychosis: is there more to early intervention than intervening early? Can J Psychiatry 46:645-648. https://doi.org/10.1177/070674370104600710

76. Hoagwood K, Burns BJ, Kiser L, Ringeisen H, Schoenwald SK (2001) Evidence-based practice in child and adolescent mental health services. Psychiatr Serv 52:1179-1189. https://doi. org/10.1176/appi.ps.52.9.1179

77. Drancourt N, Etain B, Lajnef M, Henry C, Raust A, Cochet B, Mathieu F, Gard S, Mbailara K, Zanouy L, Kahn JP, Cohen RF, Wajsbrot-Elgrabli O, Leboyer M, Scott J, Bellivier F (2013) Duration of untreated bipolar disorder: missed opportunities on the long road to optimal treatment. Acta Psychiatr Scand 127:136144. https://doi.org/10.1111/j.1600-0447.2012.01917.x

78. Altamura A, Camuri G, Dell'Osso B (2013) Duration of untreated illness and duration of illness in anxiety disorders: assessment and influence on outcome. Anxiety Disord 29:111-118. https://doi. org/10.1159/000351950

79. Ghio L, Gotelli S, Marcenaro M, Amore M, Natta W (2014) Duration of untreated illness and outcomes in unipolar depression: a systematic review and meta-analysis. J Affect Disord 152-154:4551. https://doi.org/10.1016/j.jad.2013.10.002

80. Headspace. http://www.headspace.org.au. Accessed Jul 2018

81. Jigsaw. http://www.jigsaw.ie. Accessed Jul 2018

82. Youth Space. http://www.youthspace.me. Accessed Jul 2018

83. Foundry. http://www.foundrybc.ca. Accessed Jul 2018

84. Iyer SN, Boksa P, Lal S, Shah J, Marandola G, Jordan G, Doyle M, Joober R, Malla AK (2015) Transforming youth mental health: a Canadian perspective. Ir J Psychol Med 32:51-60. https://doi. org/10.1017/ipm.2014.89

85. Youth Wellness Hubs Ontario. http://www.youthhubs.ca. Accessed Jul 2018

86. Plaistow J, Masson K, Koch D, Wilson J, Stark RM, Jones PB, Lennox BR (2014) Young people's views of UK mental health services. Early Interv Psychiatry 8(1):12-23. https://doi.org/10.1111/ eip. 12060

87. Lloyd-Evans B, Crosby M, Stockton S, Pilling S, Hobbs L, Hinton M, Johnson S (2011) Initiatives to shorten duration of untreated psychosis: systematic review. Br J Psychiatry 198(4):256-263. https://doi.org/10.1192/bjp.bp.109.075622

88. Gulliver A, Griffiths KM, Christensen H (2010) Perceived barriers and facilitators to mental health help-seeking in young people: a systematic review. BMC Psychiatry 10:113-113. https://doi. org/10.1186/1471-244X-10-113

89. Rickwood D, Deane FP, Wilson CJ, Ciarrochi J (2005) Young people's help-seeking for mental health problems. Aust e-J Adv Ment Health 4(3):218-251. https://doi.org/10.5172/jamh.4.3.218

90. Saxena S, Thornicroft G, Knapp M, Whiteford H (2007) Resources for mental health: scarcity, inequity, and inefficiency. Lancet 370(9590):878-889. https://doi.org/10.1016/S0140 -6736(07)61239-2

91. Patel V, Flisher AJ, Nikapota A, Malhotra S (2008) Promoting child and adolescent mental health in low and middle income countries. J Child Psychol Psychiatry 49(3):313-334. https://doi. org/10.1111/j.1469-7610.2007.01824.x

92. Andersen RM (1995) Andersen and Newman framework of health services utilization. J Health Soc Behav 36:1-10. https://doi. org/10.1111/pme.12756

93. Pescosolido BA (1992) Beyond rational choice: the social dynamics of how people seek help. Am J Sociol 97(4):1096-1138. https ://doi.org/10.1086/229863

94. Coughlin SS (1990) Recall bias in epidemiologic studies. J Clin Epidemiol 43(1):87-91. https://doi.org/10.1016/08954356(90)90060-3

95. Hetrick SE, Bailey AP, Smith KE, Malla A, Mathias S, Singh SP, O'Reilly A, Verma SK, Benoit L, Fleming TM (2017) Integrated (one-stop shop) youth health care: best available evidence and future directions. Med J Aust 207(10):S5-S18. https://doi. org/10.5694/mja17.00694

96. Birnbaum ML, Candan K, Libby I, Pascucci O, Kane J (2016) Impact of online resources and social media on help-seeking behaviour in youth with psychotic symptoms. Early Interv Psychiatry 10:397-403. https://doi.org/10.1111/eip.12179

97. Morgan C, Mallett R, Hutchinson G, Leff J (2004) Negative pathways to psychiatric care and ethnicity: the bridge between social science and psychiatry. Soc Sci Med. https://doi.org/10.1016/ S0277-9536(03)00233-8 